\title{
Bond characteristics of steel fiber and deformed reinforcing steel bar embedded in steel fiber reinforced self-compacting concrete (SFRSCC)
}

Research article

Farhad Aslani, Shami Nejadi

Centre for Built Infrastructure Research, School of Civil and Environmental Engineering, University of Technology Sydney, Australia

Received 26 January 2012; accepted 22 May 2012

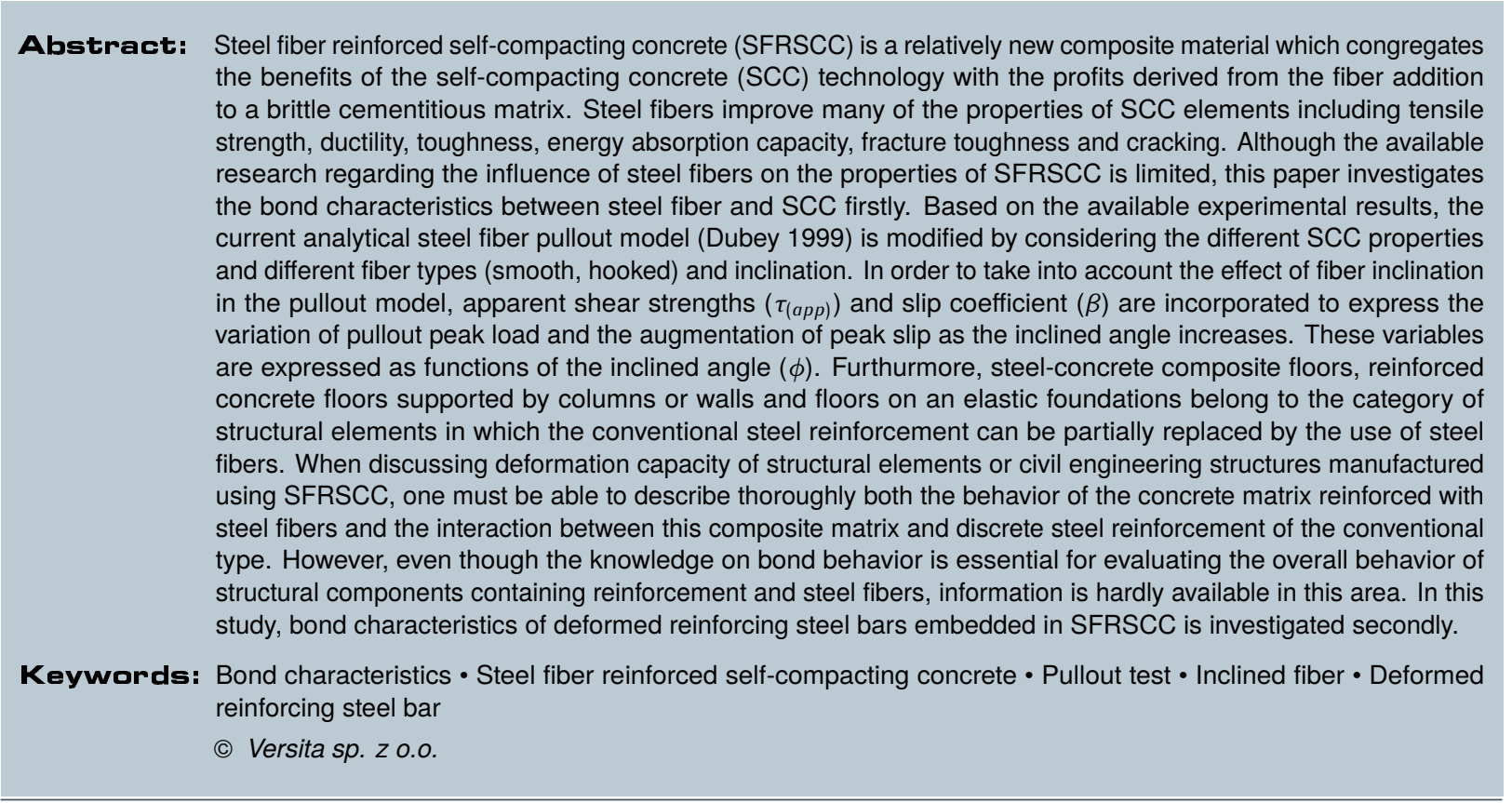

\section{Introduction}

\subsection{Steel fiber and matrix made of self- compacting concrete}

Self-compacting concrete (SCC) can be placed and compacted under its own weight with little or no compaction.
It is cohesive enough to be handled without segregation or bleeding. It can be used to facilitate and ensure proper filling of complex and multipart formworks and consequently offers good structural performance in heavily reinforced structural members. Modification in the mix design of self-compacting concrete may significantly influence the material's mechanical properties. Steel fibers can improve 
many of the properties of SCC elements including tensile resistance and crack control, ductility, toughness, energy absorption capacity, and resistance to fatigue. In the fresh state, steel fiber reinforced self-compacting concrete (SFRSCC) homogeneously spreads due to its own weight, without any additional compaction energy, due to filling and passing ability, as well as segregation resistance. In the hardened state, the addition of fibers to brittle cementitious matrix mostly contributes to the improvement of the impact resistance and the energy absorption capacity [1]. Steel fiber reinforced concrete (SFRC) resists tensile forces through a composite action of the matrix and the fibers. A part of the tensile force is resisted by the matrix, while the other part is resisted by the fibers. Each of these resistances are determined by the stress transfer at the fiber-matrix interface, which is achieved by the bond defined as the shear stress acting at the interface. Before any cracking has taken place, elastic stress transfer is dominant. At more advanced stages of loading, debonding across the interface usually takes place, and frictional slip governs the stress transfer at the interface. Therefore, the mechanical properties of SFRC, especially its tensile strength, tensile stress-strain curve, and toughness, are influenced by the bond characteristics at the fiber-matrix interface [2-5] sensitively. Accordingly, it is necessary to study the bond properties between the matrix and fiber prior to examining the various mechanical properties of SFRC [6].

The bond characteristics depends on several factors including the orientation of the fibers relative to the direction of the applied load, embedded length of the fibers, shape of the fibers, and strength of the matrix. Many researches concerning bond properties have been conducted to reveal the effects of the parameters related to fiber geometry or strength of the matrix [7-15]. Several models to predict the pullout behavior of fibers have been proposed [16-21] so far. However, the inclination angle of a fiber in a cementitious matrix has a strong influence on the pullout resistance. Although several researchers have performed experiments to investigate the effect of the fiber inclination angle, the focus was mostly on the peak pullout load. Thus, its effect is still disputable $[4,13-15]$. It is generally agreed that the effect of fiber inclination angle on the pullout load and pullout energy totally depends on the fiber aspect ratio (ratio of fiber length to equivalent fiber diameter), fiber shape (straight, hooked, corrugated etc.), and material properties such as yield strength whether the fiber material is metallic or synthetic [6].

Based on the choice of criterion which is used for the fiber-matrix interfacial debonding, the theoretical analysis of the fiber pullout problem can be classified into two distinct approaches: strength based and fracture mechanics based approaches. Theoretical models based on the former approach use maximum interfacial shear stress as the interfacial debonding criterion. Therefore, when the interfacial shear stress exceeds the interfacial bond strength, debonding is supposed to occur. On the other hand, in the theoretical models based on the concepts of fracture mechanics, the debonded zone is considered as an interfacial crack, and the extension of the crack depends on the energy criterion that should be satisfied [22].

\subsection{Deformed reinforcing steel bars embed- ded in steel fiber reinforced self-compacting concrete}

An overview of the practical applications of SFRC shows that depending on the type of structure, the use of the steel fibers can either reduce the required amount of conventional steel reinforcement or in some cases replace it altogether, while maintaining satisfactory performance of the structure [23]. Steel-concrete composite floors, reinforced concrete floors supported by columns or walls and floors on an elastic foundations belong to the category of structural elements in which the conventional steel reinforcement can be partially replaced by the use of SFRC. In these cases the use of steel fibers is in-tended to reduce opening of creep and shrinkage cracks and to increase the speed of construction works. Steel reinforcement is still needed there to guarantee sufficient deformation capacity and load carrying capacity at the supports. Besides the traditional use of fibers for controlling cracks in e.g. slabs and toppings, examples can be given of fiber application for load-bearing purposes. Research affirms the possibility of using fibers for structural repairs, ductile beam-column connections [24] or shear reinforcement, e.g. in order to replace conventional (web) reinforcement in I-shaped girders [25]. Also in case of prefabricated tunnels, it is possible to eliminate conventional (bending) reinforcement if SFRC is used, provided that the bending moments re-main low. However, with respect to force distribution in tunnel structures it is important to note that, under some geological circumstances or exceptional loading situations, it is possible to find sections where stresses due to bending dominate the stress distribution and even absence of a normal force is possible. In such cases it is not feasible to apply steel fibers as main reinforcement. Therefore, in order to provide a general structural solution for future tunnel planning it is often suggested to combine the best properties of both steel fibers and ordinary steel reinforcement. This approach results in a combination of steel fiber reinforcement and conventional steel reinforcement.

The number of applications of SFRC increased over the past few years. However, SRFC can be efficiently and safely applied in a wide variety of structures provided 


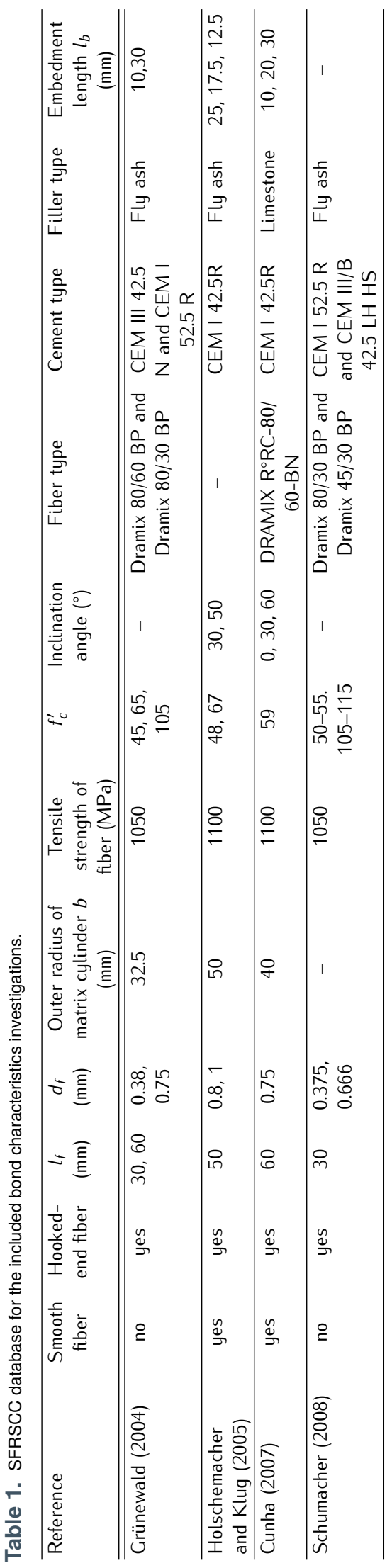

that it is fully clear in which way the use of SFRC contributes to the resistance of the structure to the applied load, both in terms of load carrying capacity and deformability. Considering that frequently a combination of both types of reinforcement is applied (e.g. conventional steel reinforcement used as main reinforcement and steel fibers used as detailing reinforcement or for durability purposes), the behavior of structural elements, which combine both types of reinforcement, should be thoroughly investigated. If the design of civil engineering structures has to be cost saving, an optimum between both types of reinforcement has to be aimed at. This can be achieved by keeping the main reinforcement of a conventional type as simple and as effective as possible and supplementing it with steel fiber reinforcement added in adjusted quantities and tuned to specific load cases [26].

When discussing deformation capacity of structural elements or civil engineering structures manufactured using SFRC, one must be able to describe thoroughly both the behavior of the concrete matrix reinforced with steel fibers and the interaction between this composite matrix and discrete steel reinforcement of the conventional type. Yet, even though the knowledge on bond behavior is essential for evaluating the overall behavior of structural components containing reinforcement and steel fibers, information is hardly available in this area.

\section{Research significance}

- Although the available research concerning the influence of steel fibers on the properties of SFRSCC is limited, this research investigates the bond characteristics between steel fiber and the matrix made of SCC. The objectives of the present research are: (a) modifying the aligned fiber pullout model based on the available experimental results of SFRSCC; (b) proposing a fiber pullout model allowing for the fiber inclination utilizing the available experimental results; (c) including the influence of the different fiber types (smooth, hooked), fiber inclination and fiber embedment length influence in the fiber pullout models.

- For bond behavior is essential for evaluating the overall behavior of structural components containing reinforcement and steel fibers, the another main objective of this study is to analytically evaluate the development strength of reinforcing bars in tension by incorporating a local bond-stress slip law derived more accurately using SFRSCC experimental results. Based on the results of this analytical study and available experimental data, a design expression 
Table 2. Experimental results from the Grünewald [27].

\begin{tabular}{cccccccc}
\hline$l_{b}$ & Fiber & \multicolumn{5}{c}{ Peak Pullout Force (N) } \\
\cline { 3 - 8 }$(\mathrm{mm})$ & type & SCC (B45) & SCC (B65) & SCC (B105) & CC (B45) & CC (B65) & CC (B105) \\
\hline \hline 10 & $80 / 30$ & 177.6 & 193.2 & 181.4 & 131.9 & 164.4 & 176.6 \\
30 & $80 / 60$ & 496.0 & 614.9 & 624.8 & 510.4 & 529.3 & 626.5 \\
10 & $80 / 60$ & 557.4 & 590.4 & 661.6 & 498.9 & 488.9 & 611.9 \\
\hline$l_{b}$ & Fiber & \multicolumn{5}{c}{ Average Hook Force (N) } \\
\cline { 3 - 8 }$(\mathrm{mm})$ & type & SCC (B45) & SCC (B65) & SCC (B105) & CC (B45) & CC (B65) & CC (B105) \\
\hline \hline 10 & $80 / 30$ & 109.3 & 110.9 & 103.8 & 73.5 & 87.2 & 106.6 \\
30 & $80 / 60$ & 386.8 & 462.2 & 464.7 & 383.7 & 403.5 & 446.3 \\
10 & $80 / 60$ & 378.2 & 427.5 & 446.4 & 353.9 & 360.4 & 424.0 \\
\hline$l_{b}$ & Fiber & \multicolumn{7}{c}{ Frictional Force (N) } \\
\cline { 3 - 8 }$(\mathrm{mm})$ & type & SCC (B45) & SCC (B65) & SCC (B105) & CC (B45) & CC (B65) & CC (B105) \\
\hline \hline 10 & $80 / 30$ & 32.3 & 23.6 & 24.4 & 17.0 & 16.4 & 29.5 \\
30 & $80 / 60$ & 175.6 & 215.8 & 206.4 & 181.6 & 186.5 & 143.8 \\
10 & $80 / 60$ & 157.0 & 227.7 & 136.5 & 186.2 & 155.9 & 137.3 \\
\hline
\end{tabular}

was proposed to evaluate the contribution of steel fiber reinforcement to the development strength of reinforcing bars in tension.

\section{Database for bond characteris- tics of the SFRSCC experimental tests}

The experimental results included in the database are developed mainly from Grünewald [27], Holschemacher and Klug [28], Cunha [29], and Schumacher [30] studies. It includes information regarding the composition of the mixtures, fresh properties of SFRSCC and testing methodology and conditions. However, it should be emphasized that this aspect has not been investigated as broadly as the other aspects of SFRSCC therefore the published experimental data is still not very extensive [31].

Using experimental data results from different sources can frequently be problematic for the following reasons: (a) there is often insufficient information regarding the exact composition of the concrete mixtures; (b) the size of the specimens, curing conditions, and testing methodology vary between the different investigations and, in some cases, this information is not fully indicated; (c) in many cases it is difficult to extract the relevant experimental values because the published results are incomplete or presented in graphical form and the data values have to be extrapolated. Table 1 presents a general summary of the fiber shape (smooth or hooked-end), fiber length $\left(l_{f}\right)$ and diameter $\left(d_{f}\right)$, outer radius of the matrix cylinder $b$, tensile strength of fiber, compressive strength of concrete $\left(f_{c}^{\prime}\right)$, inclination angle, fiber type, cement type, filler type and embedment length $\left(l_{b}\right)$.
In Table 2, the Grünewald [27] experimental results are summarized. It includes the peak pullout force, the average force (the length of the hook is equal to the displacement which fiber requires to completely enter the straight channel) and the average frictional force (up to the slip at which the load rapidly dropped to zero). In addition, it includes different types of fiber, embedded lengths, types of concrete (SCC or conventional concrete (CC)) and compressive strengths $(45,65,105 \mathrm{MPa})$.

In Table 3, the Holschemacher and Klug [28] experimental results are included. It summarizes the peak pullout force, slip at peak pullout force for different types of fiber (long and short end hook, smooth, $l_{f} / d_{f}=50$ and $l_{f} / d_{f}=62.5$ ), concrete ages ( 3 days, 7 days and 28 days) and concrete types (SCC or CC).

In Table 4, the Cunha [29] experimental results including the peak pullout force, slip at peak pullout force for different types of fiber (hooked and smooth), inclination angle and embedment length are summarized.

In Table 5, the Schumacher [30] experimental results, the deformation controlled pullout tests are presented for on reinforcing bars embedded in plain and fiber reinforced selfcompacting concrete over a short embedment length. The influence of the following parameters on the bond behavior is investigated: fiber volume, fiber aspect ratio, concrete cover, way of manufacturing (cast and sawn specimens) and concrete compressive strength. Pullout tests performed on single $10 \mathrm{~mm}$ diameter ribbed bars embedded along three times the bar diameter (i.e. $30 \mathrm{~mm}$ ) in $200 \mathrm{~mm}$ cubes.

From investigation conducted by Aslani and Nejadi [31] on the bond characteristics of SFRSCC experimental tests, the following conclusions can be derived: a) the maximum pullout force and the average force within the length of the hook of SCC are significantly higher than CC. The 
Table 3. Experimental results from the Holschemacher and Klug [28].

\begin{tabular}{lcc}
\hline & $\begin{array}{c}\text { Peak Pullout Force } \\
(\mathrm{N})\end{array}$ & $\begin{array}{c}\text { Slip at Peak Pullout } \\
\text { Force }(\mathrm{mm})\end{array}$ \\
\hline Mixture type & $\begin{array}{c}\text { Hooked fiber } \\
\left(l_{f} / d_{f}=50\right)\end{array}$ & $\begin{array}{c}\text { Hooked fiber } \\
\left(l_{f} / d_{f}=50\right)\end{array}$ \\
\hline \hline SCC & 469.3 & 0.759 \\
CC & 316.0 & 1.130 \\
\hline Mixture type & Fiber $\left(l_{f} / d_{f}=50\right)$ & Fiber $\left(l_{f} / d_{f}=50\right)$ \\
\hline \hline SCC (Long end hook fiber) & 544.4 & 1.251 \\
SCC (Short end hook fiber) & 610.6 & 1.063 \\
SCC (Smooth fiber) & 138.9 & 1.184 \\
\hline Concrete age & Long end hook fiber & Long end hook fiber \\
& $\left(l_{f} / d_{f}=50\right)$ & $\left(l_{f} / d_{f}=50\right)$ \\
\hline \hline SCC (3 days) & 455.8 & 1.426 \\
SCC (7 days) & 486.2 & 1.345 \\
SCC (28 days) & 546.5 & 1.244 \\
\hline Concrete age & Long end hook fiber & Long end hook fiber \\
& $\left(l_{f} / d_{f}=62.5\right)$ & $\left(l_{f} / d_{f}=62.5\right)$ \\
\hline \hline SCC (3 days) & 326.0 & 0.857 \\
SCC (7 days) & 300.7 & 1.148 \\
SCC (28 days) & 294.5 & 1.421
\end{tabular}

Table 4. Experimental results from the Cunha [29].

\begin{tabular}{cccccc}
\hline & & \multicolumn{2}{c}{ Peak Pullout } & \multicolumn{2}{c}{ Slip at Peak } \\
& & \multicolumn{2}{c}{ Force $(\mathrm{N})$} & \multicolumn{2}{c}{ Pullout Force $(\mathrm{mm})$} \\
\cline { 3 - 6 } & $\begin{array}{c}l_{b} \\
(\mathrm{~mm})\end{array}$ & $\begin{array}{c}\text { Hooked } \\
\text { fiber }\end{array}$ & $\begin{array}{c}\text { Smooth } \\
\text { fiber }\end{array}$ & $\begin{array}{c}\text { Hooked } \\
\text { fiber }\end{array}$ & $\begin{array}{c}\text { Smooth } \\
\text { fiber }\end{array}$ \\
\hline \hline \multirow{3}{*}{ Angle $\left(0^{\circ}\right)$} & 10 & 321.8 & - & 0.59 & - \\
& 20 & 347.8 & 77.4 & 0.65 & 0.12 \\
& 30 & 388.2 & 155.2 & 0.69 & 0.25 \\
\hline \multirow{3}{*}{ Angle $\left(30^{\circ}\right)$} & 10 & 360.9 & - & 0.94 & - \\
& 20 & 400.1 & 173.5 & 1.00 & 0.19 \\
& 30 & 416.0 & 203.7 & 0.80 & 0.38 \\
\hline \multirow{3}{*}{ Angle $\left(60^{\circ}\right)$} & 10 & 342.0 & 154.2 & 2.40 & 3.34 \\
& 20 & 335.2 & 172.8 & 2.33 & 2.02 \\
& 30 & 365.1 & 189.4 & 2.64 & 2.17 \\
\hline
\end{tabular}

frictional resistance was also larger in most cases but a few results were found to be lower; b) the compressive strength of concrete influences the pullout loads but not in the expected order of magnitude. That means by increasing the concrete age and consequently the compressive strength the ultimate load increases as well; c) the influence of the inclination of the end hook seems to be more effective than the compressive strength of SCC; $d$ the slip at peak pullout force increases with the inclination angle for both hooked and smooth fibers; e) in the larger cross-sectional area under stress, fiber with lower aspect ratio $\left(l_{f} / d_{f}\right)$ shows higher pullout loads than fiber with higher aspect ratio in SCC mixtures; f) the bond behavior of fibers embedded in SCC is more efficient than of those fibers embedded in $\mathrm{CC} ; \mathrm{g}$ ) in SCC, for both hooked and smooth aligned fibers, the configuration of the pullout load-slip curve was similar (regardless the fiber embedded length). However, the peak load and the dissipated energy increases as expected; h) in the case of aligned fibers the influence of lb is more significant on the smooth fibers, while relatively small increments are registered for the hooked end fibers; i) for both hooked and smooth fibers the highest maximum pullout load is observed for an inclination angle of $30^{\circ}$. However, the increase of the maximum pullout load with the inclination angle is more significant on the smooth fiber types; j) for SCC without fibers the direction of the casting pullout test specimens does not significantly influence the bond stress-slip relationship; $k$ ) the addition of steel fibers slightly influences the bond behavior in case of pullout bond failure and is expected to have a pronounced effect in case of splitting bond failure.

\section{Modeling of bond steel fiber and matrix made of SCC}

\subsection{Overview of the theoretical steel fiber- matrix pullout models}

Cox [32] has developed the first strength-based analytical model to describe the transfer of the stress between fiber and matrix. This model assumes that the tensile stress in the matrix is negligible if compared to those in the fiber and the shear stresses in the fiber. In addition, the shear stresses in the fiber are small compared to those in the matrix. Assuming compatibility of the fiber and matrix displacement at interface, i.e., no slip, Cox [32] derived 
Table 5. Experimental results from the Schumacher [30].

\begin{tabular}{|c|c|c|c|c|}
\hline & $\begin{array}{l}\text { Peak Pullout Force } \\
(\mathrm{N})\end{array}$ & $\begin{array}{l}\text { Slip at Peak Pullout } \\
\text { Force }(\mathrm{mm})\end{array}$ & $\begin{array}{l}\text { Peak Pullout Force } \\
(\mathrm{N})\end{array}$ & $\begin{array}{l}\text { Slip at Peak Pullout } \\
\text { Force }(\mathrm{mm})\end{array}$ \\
\hline Concrete cover $(\mathrm{mm})$ & SCC (B45) Test1 & SCC (B45) Test1 & SCC (B45) Test2 & SCC (B45) Test2 \\
\hline 15 & 1416.78 & 0.267 & 1578.5 & 0.088 \\
\hline 25 & 1755.30 & 0.555 & 1645.76 & 0.436 \\
\hline 35 & 1717.78 & 0.474 & 1809.71 & 0.430 \\
\hline 95 & 1584.78 & 0.431 & 1400.52 & 0.257 \\
\hline Concrete cover $(\mathrm{mm})$ & SCC (B105) Test1 & SCC (B105) Test1 & SCC (B105) Test2 & SCC (B105) Test2 \\
\hline 35 & 3711.76 & 0.229 & 3677.89 & 0.333 \\
\hline Concrete cover (mm) & $\begin{array}{l}\text { SCC (B45) with } \\
80 / 30 \text { fibreTest1 }\end{array}$ & $\begin{array}{l}\text { SCC (B45) with } \\
80 / 30 \text { fibreTest1 }\end{array}$ & $\begin{array}{l}\text { SCC (B45) with } \\
80 / 30 \text { fibreTest2 }\end{array}$ & $\begin{array}{l}\text { SCC (B45) with } \\
80 / 30 \text { fibreTest2 }\end{array}$ \\
\hline 15 & 1565.45 & 0.579 & 1643.6 & 0.678 \\
\hline 15s (sawn cast) & 1621.63 & 0.416 & 1373.43 & 0.513 \\
\hline 25 & 2024.97 & 0.524 & 1655.7 & 0.820 \\
\hline 25s (sawn cast) & 1877.97 & 0.726 & 1951.31 & 0.558 \\
\hline 35 & 1722.36 & 0.320 & 1678.18 & 0.792 \\
\hline 95 & 1894.73 & 0.759 & - & - \\
\hline Concrete cover $(\mathrm{mm})$ & $\begin{array}{l}\text { SCC (B45) with } \\
\text { 45/30 fibreTest1 }\end{array}$ & $\begin{array}{l}\text { SCC (B45) with } \\
\text { 45/30 fibreTest1 }\end{array}$ & $\begin{array}{l}\text { SCC (B45) with } \\
45 / 30 \text { fibreTest2 }\end{array}$ & $\begin{array}{l}\text { SCC (B45) with } \\
45 / 30 \text { fibreTest2 }\end{array}$ \\
\hline 35 & 1348.64 & 0.722 & 1599.257 & 0.454 \\
\hline Concrete cover (mm) & $\begin{array}{l}\text { SCC (B105) with } \\
80 / 30 \text { fibreTest1 }\end{array}$ & $\begin{array}{l}\text { SCC (B105) with } \\
80 / 30 \text { fibreTest1 }\end{array}$ & $\begin{array}{l}\text { SCC (B105) with } \\
80 / 30 \text { fibreTest2 }\end{array}$ & $\begin{array}{l}\text { SCC (B105) with } \\
80 / 30 \text { fibreTest2 }\end{array}$ \\
\hline 35 & 3765.51 & 0.236 & 3695.2 & 1.220 \\
\hline
\end{tabular}

analytical expressions for the axial stress distribution in the fiber and the shear stress distribution at the interface. Greszczuk [33] was the first to derive an interfacial debonding criterion using the shear-lag theory. The analytical model by Greszczuk [33] was also based on similar assumptions as Cox [32], but later postulated that at the instant when the shear strength of the interface is first attained, catastrophic debonding would occur over the entire embedded length of the fiber. However, in reality, debonding may be limited to the zone in which the elastic shear stress exceeds the adhesional shear bond strength and in those circumstances, the process of load transfer will comprise the frictional shear transfer at the debonded zone and elastic shear transfer over the remaining length of the fiber. Greszczuk's model [33] did not include the possibility of the existence of frictional bond, which constituted a major limitation of the model. Thus, his solution did not consider the stabilization of the debonding process that may take place due to the existence of frictional shear bond at the debonded interface.

Further, Lawrence [34] extended the theory developed by Greszczuk [33] by taking into account the process of progressive debonding of the fiber-matrix interface. He suggested that the maximum fiber pullout load would occur at the instant when debonding of that part of fiber length where the elastic bond is still intact takes place in a catastrophic manner. The model developed by Lawrence [34] includes the effects of both the interfacial elastic shear stresses and the frictional shear stresses, and it recognizes the conditions for either a gradual, or an instantaneous debonding of the interface. He has shown that the form of the distribution of the shear stress and the load along the fiber length depends upon the elastic properties of constituents and the fiber embedded length. In this model, interfacial frictional shear stresses over the entire debonded zone were assumed to remain constant.

Gopalaratnam and Shah [35] with regard to interfacial shear-stresses made similar assumptions to those made by Lawrence [34] to obtain the solution to the fiber pullout problem. Thus, this model takes into consideration the following: the existence of interfacial elastic shear stresses prior to the inception of fiber-matrix interfacial debonding, the existence of both the interracial elastic shear stresses and the interfacial frictional shear stresses when the fibermatrix interface is partially debonded, and the existence of interracial frictional shear stresses after the fiber-matrix interface has completely debonded and is pulling out.

Models developed by Gopalratnam and Shah [35], Nammur et al. [36], Gopalaratnam and Cheng [37], Stang et al. [38] also took into account the combined stress transfer mechanisms. It is apparent that the shear stresses (both elastic and frictional) that develop parallel to the fiber-matrix interface are of extreme importance in controlling the fibermatrix stress transfer mechanism. However, stresses and 
strains may also develop normal to the fiber-matrix interface as a result of Poisson's effect, volume change, and multiaxial loading. They may induce considerable variations in the resistance of frictional slip, which is sensitive to normal stress. A comprehensive approach to the stresstransfer problem therefore requires simultaneous treatment of all the above-mentioned effects, including elastic shear transfer, frictional slip, debonding and normal stresses and strains.

Analytical models developed by Takaku and Arridge [39] and Hsueh [40-42] are more comprehensive than the previously cited models since these models take into consideration the influence of Poisson's contraction of the fiber on the pullout test. However, these aspects were considered in the analysis only after the occurrence of complete interfacial debonding (i.e., in the fiber pullout case as explained later). Thus, the influence of Poisson's contraction during progressive debonding remained unaccounted, which constituted a major limitation of this model. The model by Hsueh [40] considers Poisson's effect during progressive debonding, however the analysis and the closed-form solutions presented are complex to use.

Furthermore, Nammur and Naaman [19] proposed an analytical model of the bond at the interface between steel fibers and cementitious composites, assuming an idealized bond-slip relationship. The assumed relationship is bilinear and elastic-perfectly frictional. This model was limited with bond stress in the interface and does not deal with the pullout behavior. Naaman et al. [20] proposed an analytical solution for the bond behavior using the relationship between the bond behavior curve and the shear stress-slip curve at the interface. The authors also adopted values of the post-debonding frictional stress on the slip based on experimental results instead of the constant value assumed in Nammur and Naaman [19]. The fiber pullout model introduced by Nammur et al. [36] is a cohesive interface type model. A cohesive interface type model assumes that only relative displacements between the fiber and the matrix can activate the stress transfer at the interface. Also, in these types of models the interfacial traction is described as a function of the displacement discontinuity, and since there exists a unique relationship between interface traction and interface displacement discontinuity, it is not required to distinguish between the debonded and bonded interface. Since the interfacial bond due to chemical adhesion is not slip induced bond, the application of the assumed bond stress versus slip relationship in this model is limited to the cases where chemical adhesion is negligible. The other major limitation of this model is that it assumes a constant value of interfacial shear stress at the debonded face. Applying the bond stress versus slip constitutive relationship to a cylindrical fiber-matrix coaxial pullout model, relationships were derived for interfacial shear stress distribution, axial shear stress distribution, and fiber displacement at the various stages of pullout loading. Applying the shrink-fit theory to the problem and hypothesizing that the radial misfit between fiber and matrix decreases as fiber is pulled out of the matrix, Naaman et al. [20, 21] modified the previously developed model by Nammur et al. [36]. It has been shown that as the fiber pulled out from the matrix, the interfacial frictional shear stress at the debonded interface decreases as a result of the decrease in radial misfit.

Numerous studies have been also conducted on deformed fibers with different shapes, such as hook-shaped fibers, and analytical models were proposed by Alwan et al. [43], Chavillard [44], and Sujivorakul et al. [8].

The above discussion brings to attention the inadequacy of the existing fiber pullout models, and also the fact that a need exists for a model that realistically captures the physical phenomenon occurring during the process of fiber pullout. To model the pullout behavior of steel fiber in SFRSCC, this study applies the progressive debonding model for fiber pullout proposed by Dubey [22], which appears to be the most suitable model for this composite. This fiber pullout model considers the evolution of the interfacial coefficient of friction during the process of fiber pullout. Additionally, the proposed model takes into account the following aspects that are either considered or ignored in the earlier models: 1) dependence of the initial debonding stress on the embedded fiber length; 2) radial dependence of the axial stress in the matrix; 3) explicit inclusion of the interfacial properties such as the contact stress' and the coefficient of friction; 4) poisson's effect (in the event of a debonded fiber).

The Dubey's [22] model is briefly described below. This model has been explained in detail in Dubey [22]. Consider a fiber of radius $a$ and Length $L$ embedded at the centre of the matrix coaxial cylinder with inner radius a and outer radius $b$. A cylindrical coordinate system is selected so that the z-axis corresponds to the fiber axial direction and $r$-axis corresponds to the radial direction. The embedded end of the fiber is located at $z=0$, and the other end where the fiber exits the matrix is located at $z=L$. The exit-end of the fiber (i.e., at $z=L$ ) is subjected to the tensile stress $\sigma_{0}$. Both fiber and matrix are assumed to be elastic. Recall that transfer of the stress between the fiber and the matrix is via interfacial shear stresses (see Figure 1).

In this model, the entire pullout process can be divided into three stages:

1. As shown in Figure 1, fiber completely bonded along it's length: during stage 1, fiber and matrix displacements at the interface remain compatible, and the resistance to fiber pullout is derived from the adhe- 


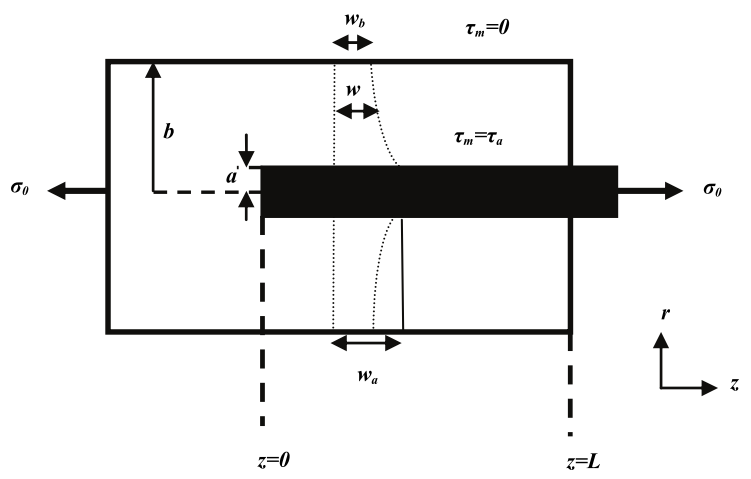

The matrix shear stress, $\tau_{m}$, at any radial distance, $r$, can be expressed as:

$\tau_{m}=\left[\frac{b-r}{b-a}\right] \frac{a}{r} \tau_{a} \quad r \geq a$

If $w_{m}$ represents the displacement of matrix in the axial direction, the corresponding shear stress in the matrix (ignoring the radial displacements) is given by: $\tau_{m}=\frac{E_{m}}{2\left(1+v_{m}\right)} \frac{d w_{m}}{d r}$;

The interfacial shear stress:

$$
\tau_{a}=\frac{E_{m}\left(w_{b}-w_{a}\right)}{2\left(1+v_{m}\right) a\left[\frac{b}{(b-a)} \log \left(\frac{b}{a}\right)-1\right]}
$$

$w_{a}$ and $w_{b}$ are the axial displacement in the matrix at $r=a$ and $r=b$; The shear stress in the matrix:

$$
\tau_{m}=\frac{E_{m}\left(w_{b}-w_{a}\right)(b-r)}{2\left(1+v_{m}\right) r\left[b \log \left(\frac{b}{a}\right)-(b-a)\right.} ; \quad(1-4) \quad w_{m}=w_{a}+\frac{w_{b}-w_{a}}{b \log \left(\frac{b}{a}\right)-(b-a)}\left[b \log \left(\frac{r}{a}\right)+a-r\right] ;
$$

The axial stress in the matrix: $\left.\sigma_{m}=E_{m} \frac{d w_{m}}{d z} ;(1-6) \quad \sigma_{m}=\frac{E_{m}}{E_{f}} \sigma_{f}+\frac{\sigma_{b}-\frac{E_{m}}{E_{f}} \sigma_{f}}{\left[b \log \left(\frac{b}{a}\right)-(b-a)\right.}\right]\left[b \log \left(\frac{r}{a}\right)+a-r\right]$;

The axial stress in the matrix $\sigma_{m=b}$,

$$
\begin{gathered}
\sigma_{b}=\frac{\sigma_{0}}{\eta}-\left[\frac{\gamma+\alpha-\gamma \eta \alpha}{\gamma \eta}\right] \sigma_{f}(1-8) ; \quad \alpha=\frac{E_{m}}{E_{f}}(1-9) ; \quad \gamma=\frac{a^{2}}{b^{2}-a^{2}} \\
\eta=\frac{2}{a^{2}\left[b \log \left(\frac{b}{a}\right)-(b-a)\right]}\left\{b\left[\frac{b^{2}}{2} \log \left(\frac{b}{a}\right)-\frac{\left(b^{2}-a^{2}\right)}{4}\right]+\frac{a\left(b^{2}-a^{2}\right)}{2}-\frac{\left(b^{3}-a^{3}\right)}{3}\right\}
\end{gathered}
$$

Fiber Axial Stress Distribution:

$$
\begin{array}{r}
\sigma_{f}=\frac{\sigma_{0}}{\gamma+\alpha-\gamma \eta \alpha+\alpha \eta}\left[(\alpha-\gamma \eta \alpha+\alpha \eta) \frac{\sinh (\beta z)}{\sinh (\beta L)}-\gamma \frac{\sinh [\beta(L-z)]}{\sinh (\beta L)}+\gamma\right] \\
\beta=\left[\frac{\theta}{\gamma \eta}(\gamma+\alpha-\gamma \eta \alpha)+\alpha \theta\right]^{1 / 2}
\end{array}
$$

Interfacial Shear Stress Distribution:

$$
\begin{gathered}
\tau_{a}=\frac{-a \beta \sigma_{0}}{2(\gamma+\alpha-\gamma \eta \alpha+\alpha \eta)}\left[(\alpha-\gamma \eta \alpha+\alpha \eta) \frac{\cosh (\beta z)}{\sinh (\beta L)}+\gamma \frac{\cosh [\beta(L-z))}{\sinh (\beta L)}\right] \\
U_{b}=\frac{\sigma_{0}}{E_{f}(\gamma+\alpha-\gamma \eta \alpha+\alpha \eta)}\left[(\alpha-\gamma \eta \alpha+\alpha \eta-\gamma) \frac{\cosh (\beta L)}{\beta \sinh (\beta L)}+\gamma L\right]
\end{gathered}
$$

Fiber Displacement:

For a two-sided pullout test, fiber displacement is given by:

$$
U_{b}=\frac{2 \sigma_{0}}{E_{f}(\gamma+\alpha-\gamma \eta \alpha+\alpha \eta)}\left[(\alpha-\gamma \eta \alpha+\alpha \eta-\gamma) \frac{\cosh (\beta L)}{\beta \sinh (\beta L)}+\gamma L\right](1-16)
$$

Debounding criterion and initial debounding stress: $\sigma_{d}=\frac{-2 \tau_{s}(\gamma+\alpha-\gamma \eta \alpha+\alpha \eta)}{a \beta}\left[\frac{(\alpha-\gamma \eta \alpha+\alpha \eta) \cosh (\beta L)}{\sinh (\beta L)}\right]^{-1}(1-17)$

Figure 1. Stage 1 - fiber completely bonded along the length of the fiber with the relevant calculations. 

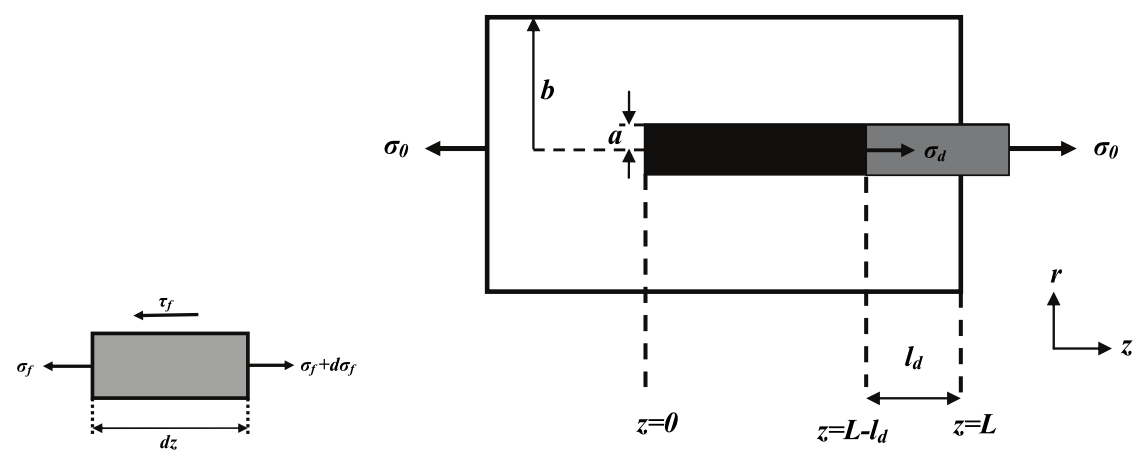

For an unstressed fibre, the relationship between the interfacial contact pressure, $\sigma_{c}$, and the radial fibrematrix misfit, $\delta_{r}$ :

$\sigma_{c}=-\frac{\delta_{r}}{\frac{a}{E_{m}}\left[\frac{a^{2}+b^{2}}{b^{2}-a^{2}}+v_{m}\right]+\frac{a}{E_{f}}\left[1-v_{f}\right]} ; \quad(2-1) \quad \Delta a=a v_{f} \frac{\sigma_{f}}{E_{f}} ; \quad(2-2) \quad \sigma_{c p}=-\frac{\left(\delta_{r}-\Delta a\right)}{\frac{a}{E_{m}}\left[\frac{a^{2}+b^{2}}{b^{2}-a^{2}}+v_{m}\right]+\frac{a}{E_{f}}\left[1-v_{f}\right]} ;$

The resultant contact pressure:

$$
\begin{aligned}
& \sigma_{c p}=\frac{-\delta_{r}}{\frac{a}{E_{m}}\left[\frac{a^{2}+b^{2}}{b^{2}-a^{2}}+v_{m}\right]+\frac{a}{E_{f}}\left[1-v_{f}\right]}+\frac{v_{f} \sigma_{f}}{\frac{E_{f}}{E_{m}}\left[\frac{a^{2}+b^{2}}{b^{2}-a^{2}}+v_{m}\right]+\left[1-v_{f}\right]} ; \\
& \sigma_{c p}=\sigma_{c}+w \sigma_{f} ; \quad(2-5) \quad w=\frac{v_{f}}{\frac{E_{f}}{E_{m}}\left[\frac{a^{2}+b^{2}}{b^{2}-a^{2}}+v_{m}\right]+\left[1-v_{f}\right]} ;
\end{aligned}
$$

The fibre axial stress:

$$
\sigma_{f}=-\frac{\sigma_{c}}{w}+\left[\sigma_{d}+\frac{\sigma_{c}}{w}\right] e^{\frac{2 w \mu\left(L-l_{d}\right)}{a}} e^{\frac{-2 w \mu z}{a}}
$$

The distribution of interfacial shear stress:

$$
\tau_{f}=\mu \sigma_{c p}=\mu\left(\sigma_{c}+w \sigma_{f}\right)
$$

The relationship between the fibre pullout stress, $\sigma_{0}$, and the debonded length, $l_{d}$ :

The total fibre displacement:

$$
\sigma_{0}=-\frac{\sigma_{c}}{w}+\left[\sigma_{d}+\frac{\sigma_{c}}{w}\right] e^{\frac{-2 \mu w l_{d}}{a}}
$$

$$
U_{p d}=\frac{\sigma_{d}}{E_{f}(\gamma+\alpha-\gamma \eta \alpha+\alpha \eta)}\left[(\alpha-\gamma \eta \alpha+\alpha \eta-\gamma) \frac{\cosh \left[\beta\left(L-l_{d}\right)\right]-1}{\beta \sinh \left[\beta\left[L-l_{d} \mid\right]\right.}+\gamma\left(L-l_{d}\right)\right]-\frac{\sigma_{c} l_{d}}{E_{f} w}-\frac{a}{2 E_{f} \mu w}\left[\sigma_{d}+\frac{\sigma_{c}}{w}\right]\left[e^{\frac{-2 \mu W l_{d}}{a}}-1\right]
$$

Bond and frictional components of pullout stress:

Catastrophic debonding:

$$
\sigma_{0}=\sigma_{0, \text { bond }}+\sigma_{0, \text { fric }}(2-11) ; \sigma_{0, \text { bond }}=\sigma_{d}(2-12) ; \sigma_{0, \text { fric }}=\left[e^{\frac{-2 \mu w l_{d}}{a}}-1\right] \sigma_{d}+\frac{\sigma_{c}}{w}\left[e^{\frac{-2 \mu w l_{d}}{a}}-1\right]
$$

$$
\begin{gathered}
\frac{d \sigma_{0}}{d l_{d}} \leq 0 ;\left|\frac{d \sigma_{0, f r i c}}{d l_{d}}\right| \leq\left|\frac{d \sigma_{0, \text { bond }}}{d l_{d}}\right|(2-14) ; \frac{d \sigma_{0}}{d l_{d}}=\left\{-\frac{2 \mu w x_{1}}{a x_{2}}-\frac{\beta x_{4}}{x_{2}}+\frac{\beta x_{1} x_{3}}{x_{2}^{2}}-\frac{2 \mu \sigma_{c}}{a}\right\} e^{\frac{-2 \mu w l_{d}}{a}} \\
x_{1}=\frac{-2 \tau_{s}(\gamma+\alpha-\gamma \eta \alpha+\alpha \eta)}{a \beta} \sinh \left[\beta\left(L-l_{d}\right)\right](2-16) ; x_{2}=(\alpha-\gamma \eta \alpha+\alpha \eta) \cosh \left[\beta\left(L-l_{d}\right)\right]+\gamma(2-1 \\
x_{3}=(\alpha-\gamma \eta \alpha+\alpha \eta) \sinh \left[\beta\left(L-l_{d}\right)\right](2-18) ; x_{4}=\frac{-2 \tau_{s}(\alpha-\gamma \eta \alpha+\alpha \eta)}{a \beta} \cosh \left[\beta\left(L-l_{d}\right)\right](2-
\end{gathered}
$$

Figure 2. Stage 2 - fiber partially bonded along its embedded length with the relevant calculations. 


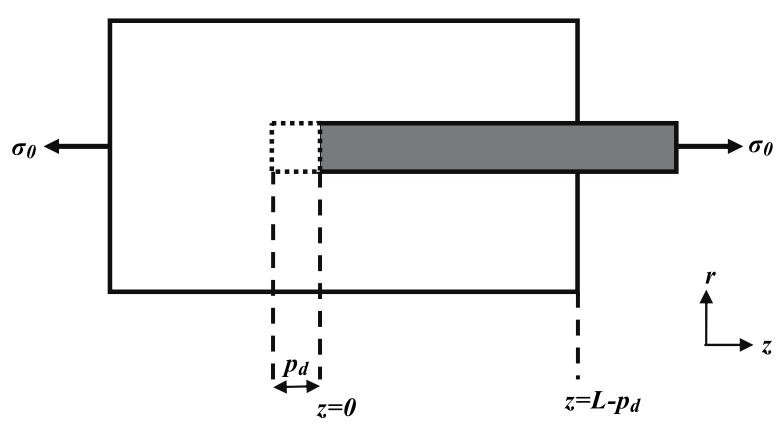

The governing differential equation of stress transfer for the pullout case has been derived by Takaku and Arridge [34]:

$$
\frac{d \sigma_{f}}{d z}+\frac{2 \mu}{a} w \sigma_{f}=\frac{-2 \mu}{a} \sigma_{c}
$$

Fiber axial stress distribution:

$$
\begin{array}{r}
\sigma_{f}=-\frac{\sigma_{c}}{w}\left[1-e^{\frac{-2 \mu w z}{a}}\right] 0 \leq z \leq L-p_{d}(3-2) \\
\tau_{f}=\mu \sigma_{c p}=\mu\left(\sigma_{c}+w \sigma_{f}\right)
\end{array}
$$

Interfacial frictional shear stress distribution

$$
\tau_{f}=\mu \sigma_{c} e^{\frac{-2 w \mu z}{a}} 0 \leq z \leq L-p_{d}(3-4)
$$

Fiber pullout stress:

$$
\begin{gathered}
\sigma_{0}=\frac{-\sigma_{c}}{w}\left[1-e^{\frac{-2 w \mu\left(L-p_{d}\right)}{a}}\right] \\
\sigma_{0}=\frac{-\sigma_{c}}{w}\left[1-e^{\frac{-2 w \mu L}{a}}\right]
\end{gathered}
$$

The initial frictional pullout stress:

Fiber displacement:

$$
U_{p d}=p_{d}-\frac{\sigma_{c}}{E_{f} w}\left[\left(L-p_{d}\right)+\frac{a}{2 \mu w}\left\{e^{\frac{-2 \mu w\left(L-p_{d}\right)}{a}}-1\right\}+p_{d}\left\{1-e^{\frac{-2 \mu w\left(L-p_{d}\right)}{a}}\right\}\right]
$$

The resultant contact stress:

$$
\sigma_{c p}=\sigma_{c}+w \sigma_{f}
$$

The interfacial contact stress;

$$
\sigma_{c}=-w \sigma_{0, a s y m p t o t i c}
$$

The work of fibre pullout, $\mu$ is the interfacial coefficient of friction:

The adhesional bond strength:

$$
W_{p}=-\frac{\pi a^{2} \sigma_{c}}{w}\left\{p_{d 2}-p_{d 1}-\frac{a}{2 w \mu} e^{\frac{-2 w \mu L}{a}}\left[e^{\frac{-2 w \mu p_{d 2}}{a}}-e^{\frac{-2 w \mu p_{d 1}}{a}}\right]\right\}
$$

$$
\begin{array}{r}
\frac{d \sigma_{d}}{d L}=\frac{-2 \tau_{s}(\gamma+\alpha-\gamma \eta \alpha+\alpha \eta)}{a \beta}\left\{\frac{[(\alpha-\gamma \eta \alpha+\alpha \eta) \cosh (\beta L)+\gamma] \beta \cosh (\beta L)}{[(\alpha-\gamma \eta \alpha+\alpha \eta) \cosh (\beta L)+\gamma]^{2}}-\frac{\beta(\alpha-\gamma \eta \alpha+\alpha \eta) \sinh ^{2}(\beta L)}{[(\alpha-\gamma \eta \alpha+\alpha \eta) \cosh (\beta L)+\gamma]^{2}}\right\} \\
\left(\frac{d \sigma_{d}}{d L}\right)_{L=0}=-\frac{2 \tau_{s}}{d}(3-12) ; \tau_{s}=-\frac{a}{2}\left(\frac{d \sigma_{d}}{d L}\right)_{L=0}
\end{array}
$$

Figure 3. Stage 3 - fiber completely debonded over its embedded length and pulling out with the relevant calculations.

sional shear stresses at the interface. At the end of stage 1 , debonding of the interface is initiated at the location where the fiber enters the matrix. Closed-form solutions are derived for the fiber axial stress distribution and the interfacial shear stress distribution along the fiber length, the fiber displacement, and the initial debonding stress (i.e., the fiber pullout stress required to initiate interfacial debonding). The closed-form solution for the initial debonding stress is derived based on a maximum shear stress criterion. This solution indicates that, among other factors, the initial debonding stress depends upon fiber length and fiber elastic properties. At the end of stage 1 , interracial debonding initiates at the location where the fiber enters the matrix [22]. 
Table 6. Proposed models for the coefficient of friction $\mu$.

\begin{tabular}{ccccc}
\hline \multirow{2}{*}{$\begin{array}{c}\text { oefficient } \\
\text { of friction }\end{array}$} & \multicolumn{2}{c}{ Hooked fiber } & \multicolumn{2}{c}{ Smooth fiber } \\
\cline { 2 - 5 } & Normal strength concrete & High strength concrete & Normal strength concrete & High strength concrete \\
\hline \hline$\mu_{i}$ & 0.26 & 0.35 & 0.12 & 0.18 \\
$\mu_{s s}$ & 0.068 & 0.083 & 0.035 & 0.050 \\
\hline$c$ & & & 0.7 & $0.13 e^{-0.7 p_{d}}+0.050$ \\
\hline$\mu$ & $0.192 e^{-0.7 p_{d}}+0.068$ & $0.267 e^{-0.7 p_{d}}+0.083$ & $0.085 e^{-0.7 p_{d}}+0.035$ & \\
\hline
\end{tabular}

2. Figure 2 shows that, fiber partially bonded along its embedded length: During stage 2, progressive debonding of the interface is initiated at the location where the fiber exits the matrix. The adhesional shear stresses at the bonded interface and the frictional shear stresses at the debonded interface resist the fiber pullout. At the end of stage 2, the fiber is completely debonded along its embedded length. The influence of Poisson's contraction of fiber is taken into consideration in the analysis. It is shown that for any debond length, the fiber pullout stress is a summation of two components, the one arising due to the adhesional shear bond and the other arising due to the frictional shear bond. Closed-form solutions are derived for fiber axial stress distribution over the bonded and the debonded interfaces, interfacial adhesional shear stress distribution over the bonded interface, interfacial frictional shear stress distribution over the debonded interface, fiber pullout stress versus debond length relationship, and fiber displacement versus debond length relationship. It is demonstrated that debonding process becomes catastrophic at the instant when the fiber pullout stress begins to drop with increase in debond length. This condition is satisfied when the difference between change in the frictional component of pullout stress and the adhesional component of pullout stress resulting due to change in debond length becomes equal to zero. A closed-form solution is derived to calculate the catastrophic debond length, given the mechanical properties of constituent materials, the interfacial properties and the geometry of the pullout specimen. Closed-form solutions are also derived to calculate the peak pullout stress and the displacement corresponding to the peak pullout stress [22].

3. As shown in Figure 3, fiber completely debonded over its embedded length and is pulling out: At the end of stage 2, pullout of the fiber is initiated, and thereafter, the interfacial frictional shear stresses resist the pullout of fiber from the matrix. Closed-form solutions are derived for fiber axial stress distribution, interfacial frictional shear stress distribution, fiber pullout stress, and fiber displacement at different stages of pullout process.

The Dubey's [22] model is capable to take into account the evolution of the interfacial properties during the pullout process. This model captures the essential features of the pullout process, including the progressive interfacial debonding and Poisson's effect in the event of debonded fiber.

\subsection{Calibration of the pullout model for bond characterization of SFRSCC}

By using database for bond characteristics of SFRSCC experimental results as shown in Tables 1-4, the interfacial properties are calibrated. The coefficient of friction versus pullout distance relationship was calculated from Equations 3-10) as shown in Figure 3. In these equations, the interval between $p_{d 1}$ and $p_{d 2}$ was chosen as $0.5 \mathrm{~mm}$. Work of fiber pullout, $W_{p}$, when fiber pullout displacement increase from $p_{d 1}$ to $p_{d 2}$ can be calculated as following:

$$
W_{p}=\frac{P_{p_{d 1}}-P_{p_{d 2}}}{2} \times\left(p_{d 1}-p_{d 2}\right)
$$

where $p_{d 1}$ and $p_{d 2}$ are the rigid body displacements of the fiber in a pullout test, $P_{p_{d 1}}$ and $P_{p_{d 2}}$ are the pullout load corresponding to the pullout distance $p_{d 1}$ and $p_{d 2}$, respectively. The evolution law for the coefficient of friction can be described by the following equation:

$$
\mu=\left(\mu_{i}-\mu_{s s}\right) e^{-c p_{d}}+\mu_{s s}
$$

where $\mu_{i}$ is the initial coefficient of friction, $\mu_{s s}$ is steady state value of the coefficient of friction attained at large pullout distances and $c$ is a constant that governs the rate at which coefficient of friction decreases exponentially with increase in pullout distance [22].

By using experimental results of the database the coefficient of friction models for smooth and hooked fibers by considering normal or high strength SCC are proposed as shown in Table 6. The coefficient of friction versus pullout distance curves obtained using equations in Table 6 for smooth and hooked fibers with different lengths $(15 \mathrm{~mm}$ 


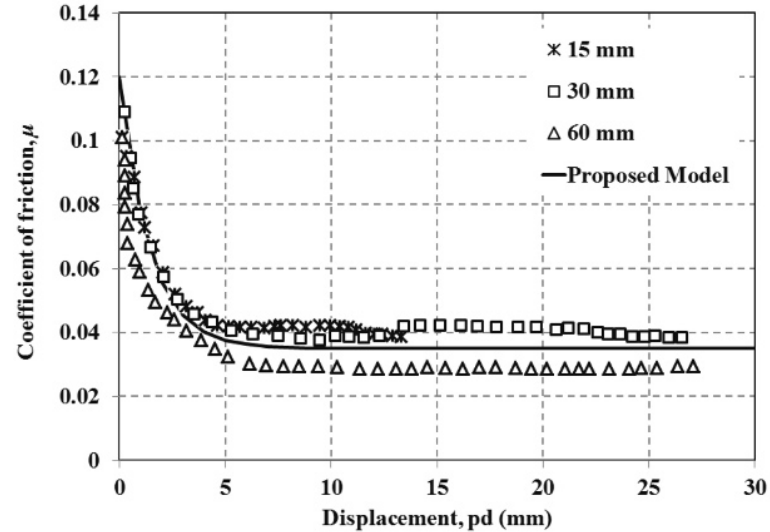

Figure 4. Coefficient of friction versus pullout displacement curves for smooth fiber and normal strength SCC.

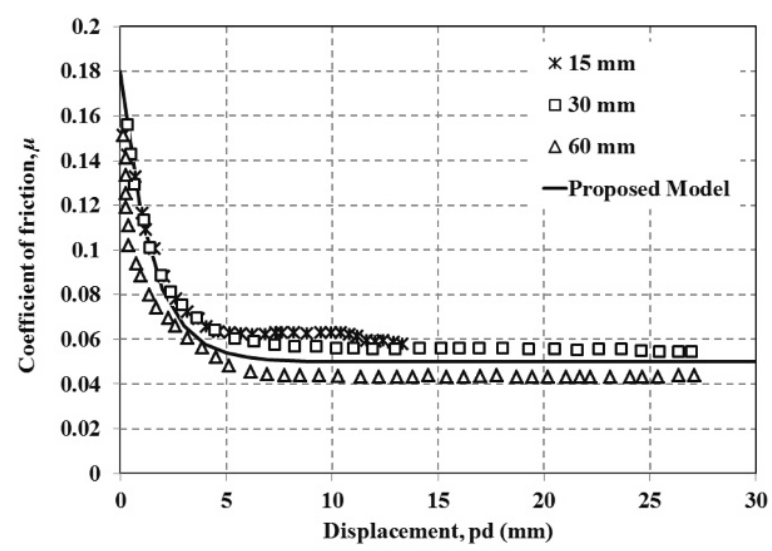

Figure 5. Coefficient of friction versus pullout displacement curves for smooth fiber and high strength SCC.

to $60 \mathrm{~mm}$ ) and normal or high strength SCC are plotted in Figures 4-7. Table 7 compares the Grünewald [27] experimental results including the measured peak pullout force with the predicted peak pullout force by utilizing the proposed coefficient of friction in the modified Dubey model [22]. As shown in Table 6, proposed model demonstrate a good agreement with the experimental results.

In addition, Figure 8 compares the Holschemacher and Klug [28] experimental results including the load-slip curves and the predicted curves by using the proposed model for smooth and hooked fiber.

\subsection{Calibration of the pullout model by allow- ing for the effect of fiber inclination angle in the bond characterization of SFRSCC}

Modeling was implemented through a comparison of the pullout test results according to change of the inclination

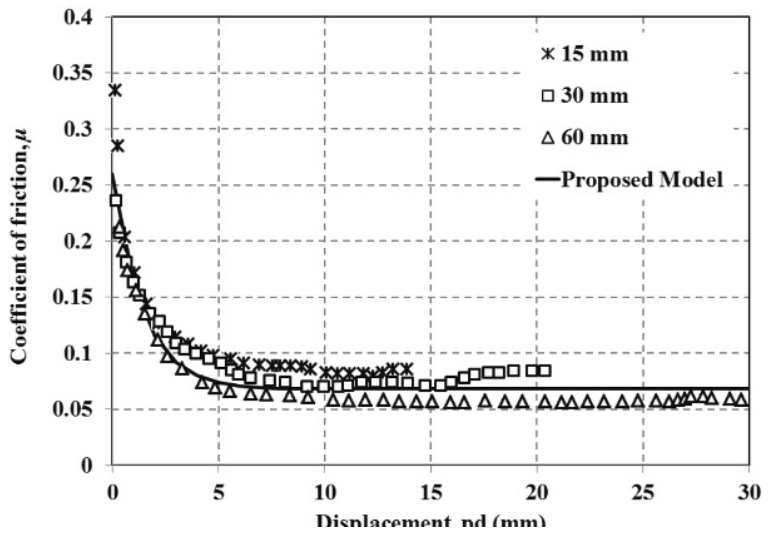

Figure 6. Coefficient of friction versus pullout displacement curves for hooked fiber and normal strength SCC.

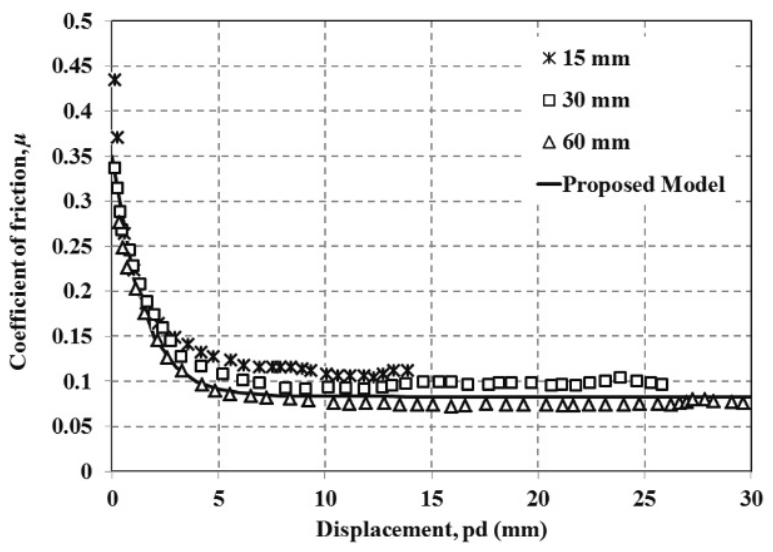

Figure 7. Coefficient of friction versus pullout displacement curves for hooked fiber and high strength SCC.

of the fibers. Modeling for the bond behavior of inclined fiber is based on the pullout model for the aligned fiber (as shown in Figures 1-3). The modeling of the bond behavior for inclined fibers considers the variation of load due to the snubbing effect and matrix spalling effect assumed that the fiber inclination angle $(\phi)$ is equal to zero (in the case where the fibers are not positioned in the tensile load direction and are inclined, the bridging force will be increased, this phenomenon is called the 'snubbing effect' $[6,15,45,46]$. This is accomplished by introducing the apparent bond strength $\left(\tau_{\max (a p p)}, \tau_{f(a p p)}\right)$ which is illustrated as a function of the inclination angle $\phi$. In addition, increase in the slip displacement is reflected by multiplying the corresponding slip to $\phi=0$ by the coefficient $\beta$, which is also a function of the inclined angle $\phi$. Table 8 gives the values of $\tau_{\max (a p p)}, \tau_{f(a p p)}$ and $\beta$ obtained through the comparison with the Cunha [29] experimental results in the database for each fiber inclination angle, as well as the corresponding $P_{\max }$. However, in this study, $\tau_{\max (a p p)}$ is 
Table 7. Comparison of experimental peak pullout force (Grünewald [27]) versus predicted peak pullout force by using proposed model.

\begin{tabular}{|c|c|c|c|c|c|}
\hline \multicolumn{6}{|c|}{ Peak pullout force $[\mathrm{N}]$} \\
\hline$l_{b}(\mathrm{~mm})$ & Fiber type & Specimen & Experimental [23] & Theoretical & Error [\%] \\
\hline \multirow{3}{*}{10} & \multirow{3}{*}{$80 / 30$} & SCC (B45) & 177.6 & 170.3 & 4.11 \\
\hline & & SCC (B65) & 193.2 & 189.4 & 1.96 \\
\hline & & SCC (B105) & 181.4 & 177.7 & 2.03 \\
\hline \multirow{3}{*}{30} & \multirow{3}{*}{$80 / 60$} & SCC (B45) & 496.0 & 499.2 & 0.64 \\
\hline & & SCC (B65) & 614.9 & 616.2 & 0.21 \\
\hline & & SCC (B105) & 624.8 & 620.6 & 0.67 \\
\hline \multirow{3}{*}{10} & \multirow{3}{*}{$80 / 60$} & SCC (B45) & 557.4 & 556.1 & 0.23 \\
\hline & & SCC (B65) & 590.4 & 596.9 & 1.1 \\
\hline & & SCC (B105) & 661.6 & 656.7 & 0.74 \\
\hline
\end{tabular}

Table 8. Proposed values of $\tau_{\max (a p p)}, \tau_{f(a p p)}, \beta$ and the corresponding $P_{\max }$ obtained through comparison of the Cunha [29] experimental results with respect to the inclination of fibers.

\begin{tabular}{ccccccc}
\hline & & \multicolumn{2}{c}{ Peak Pullout Force $(\mathrm{N})$} & \multicolumn{2}{c}{$\tau_{\max (a p p),} \tau_{f(a p p)}$} & \multirow{2}{*}{$\beta$} \\
\cline { 3 - 6 } & $\mathrm{lb}(\mathrm{mm})$ & Hooked fiber & Smooth fiber & Hooked fiber & Smooth fiber & \\
\hline \hline \multirow{3}{*}{ Angle $\left(0^{\circ}\right)$} & 10 & 321.8 & - & 1.61 & - & \\
& 20 & 347.8 & 77.4 & 1.80 & 1.77 & 1.0 \\
& 30 & 388.2 & 155.2 & 2.10 & 2.27 & \\
\hline \multirow{3}{*}{ Angle $\left(30^{\circ}\right)$} & 10 & 360.9 & - & 4.31 & - & \\
& 20 & 400.1 & 173.5 & 3.29 & 3.12 & 9.0 \\
& 30 & 416.0 & 203.7 & 1.99 & 2.34 & \\
\hline \multirow{3}{*}{ Angle $\left(60^{\circ}\right)$} & 10 & 342.0 & 154.2 & 2.62 & 3.07 & \\
& 20 & 335.2 & 172.8 & 3.33 & 3.63 & 62.40 \\
& 30 & 365.1 & 189.4 & 0.85 & 0.91 & \\
\hline
\end{tabular}

equal to $\tau_{f(a p p)}$ for each fiber inclination angle, since $\tau_{\max }$ and $\tau_{f}$ are the same for the aligned fibers. Furthermore, the Levenberg-Marquardt algorithm is selected for the nonlinear regression analysis to fit the test results with the parameters $\tau_{\max (a p p)}$ and $\tau_{f(a p p)}$. A parameter study is also performed to minimize the sum of squares of errors, as shown in Equation (3).

$$
\digamma=\left(\tau_{\max (a p p)}, \tau_{f(a p p)}\right)=\sum_{l}^{n}\left(P_{e}-P_{m}\right)^{2}
$$

where $n$ is the number of data sets, $P_{m}$ is the measured pullout load from the pullout tests, and $P_{e}=\sigma_{0} A_{f}$ is the calculated pullout load from Equation (2)-(refeq:11) as shown in Figure 2 including the parameters $\tau_{\max (a p p)}$ and $\tau_{f(a p p)}$. The parameter $\beta$ is determined by calculating $U_{\text {peak }}(\varphi) / U_{\text {peak }}(0)$ ratio obtained from the experiments as shown in Tables 4 and 8 where $U_{\text {peak }}(\varphi)$ denotes the peak slip displacement corresponding to the peak load with the inclination angle $\phi$ and $U_{\text {peak }}(0)$ is the peak slip displacement corresponding to the peak load for the aligned fiber.
Primarily, this study attempts to express $\tau_{\max (a p p)}, \tau_{f(a p p)}$ and $\beta$ as a function of $\phi$ based on the results of Table8. To express these quantities as a function of $\phi$, an allowance for the snubbing and matrix spalling effects in $P_{\max }$ is made. The snubbing effect could be defined by the following equation $[15,22,46]$ :

$$
P(\phi)=e^{f \phi} P(\phi=0)
$$

where $f$ is the snubbing friction coefficient, the value of $f$ varies with the type of the fiber and strength of the matrix. The matrix of spalling effect can be considered by the following equation, assuming that load reduction does not occur when $\phi=0$ and the pullout force does not act on the fiber when $\phi=\pi / 2$.

$$
P(\phi)=(\cos \phi)^{k} P(\phi=0)
$$

where $k$ is the spalling coefficient and $\phi$ is in radians. In order to apply the snubbing and matrix spalling effects to the bond behavior $\tau_{a p p}$ can be expressed as a function of $\phi$ using Equations (4)-(5) as following:

$$
\tau_{a p p}(\phi)=e^{f \phi}(\cos \phi)^{k} \tau(\phi=0)
$$




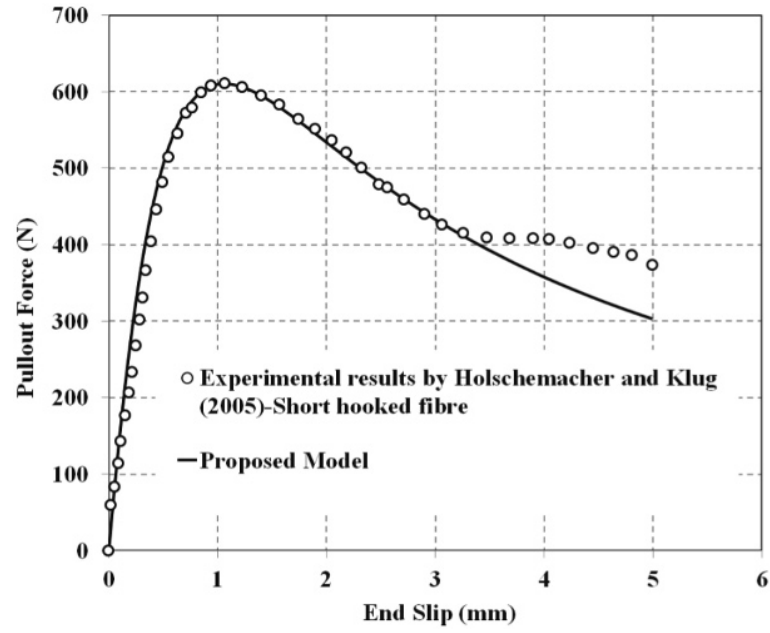

(a) $l_{f} / d_{f}=50$, short hooked fiber

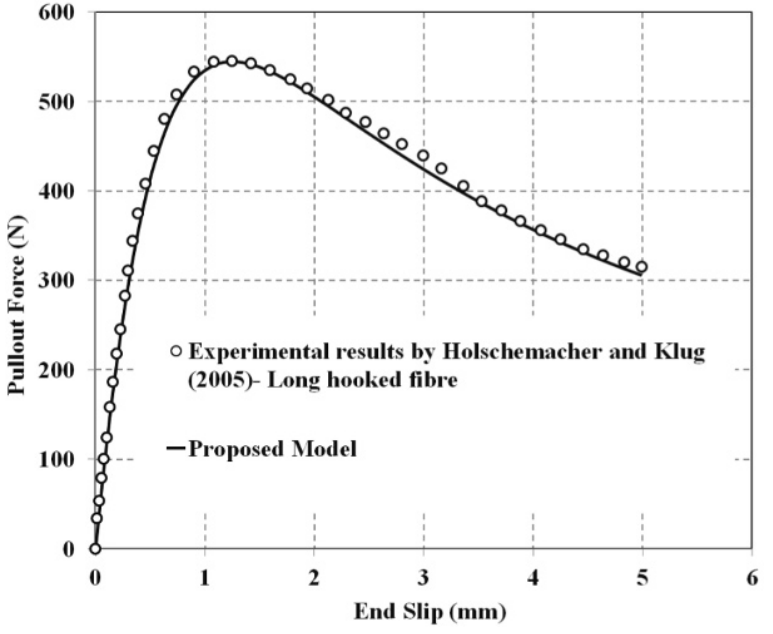

(b) $l_{f} / d_{f}=50$, long hooked fiber

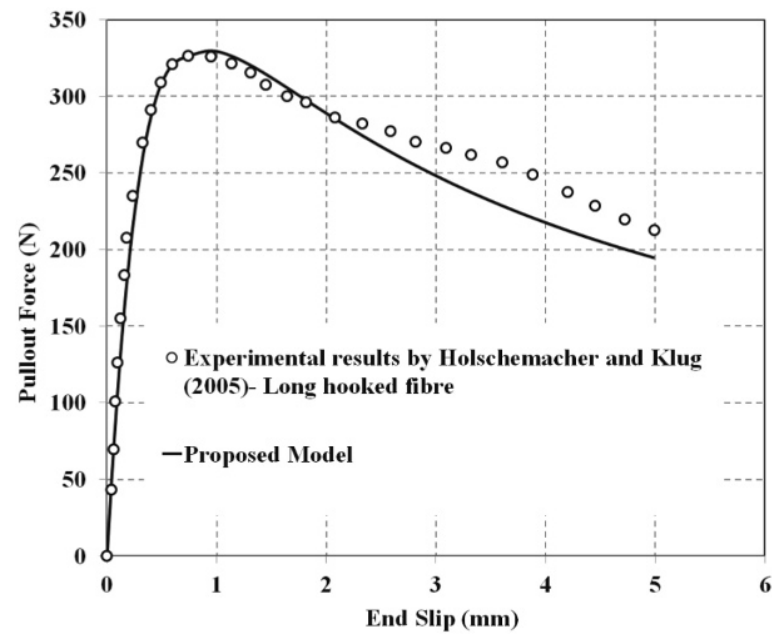

(c) $l_{f} / d_{f}=62.5$, long hooked fiber

Figure 8. Comparison of the experimentally obtained load-slip curves versus (Holschemacher and Klug [28]) predicted curves by using the proposed model.

Comparison of the Cunha [29] experimental results for smooth and hooked steel fiber with two different fiber embedment lengths (10 and $20 \mathrm{~mm}$ ) reveals that the best agreement can be proposed by utilizing Equation (7); and for embedment length $30 \mathrm{~mm}$ by utilizing Equation (8) as presented below:

$$
\begin{aligned}
& \tau_{\text {app }}(\phi)=e^{1.6 \phi}(\cos \phi)^{1.4} \tau(\phi=0) \\
& \tau_{a p p}(\phi)=e^{0.8 \phi}(\cos \phi)^{3} \tau(\phi=0)
\end{aligned}
$$

Figures 9-10 compare the shear strengths obtained by using the experimental results and Equation (2)-(5) in Figure 2. The apparent shear strengths are obtained by using Equations (7) and (8) for three different embedment length $(10,20$ and $30 \mathrm{~mm})$.
In addition, $U(\phi)$ is defined by the following expression considering both the snubbing and the effect of matrix spalling effects.

$$
\begin{aligned}
U(\phi) & =\beta U(\phi=0) \\
\beta & =1+\gamma\left(\frac{2 \phi}{\pi}\right)^{n}
\end{aligned}
$$

Comparison of the results determined by the above mentioned equations with the experimental results reveals that a good agreement can be achieved if: $n=1.8$ and $\gamma=100$ are proposed. Figu11 shows the variation of slip coefficient, $\beta$, with respect to $\phi$ (Equation (10)) using the proposed values of $n$ and $\gamma$. 


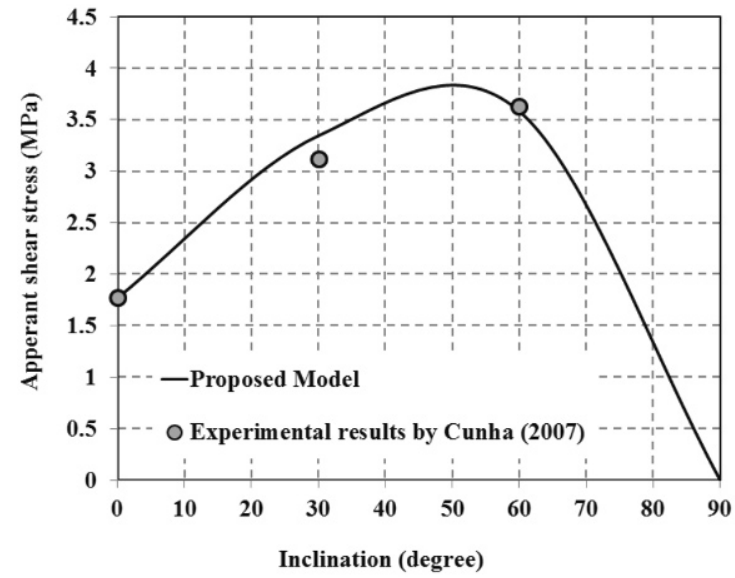

(a) $l_{b}=20 \mathrm{~mm}$, smooth fiber

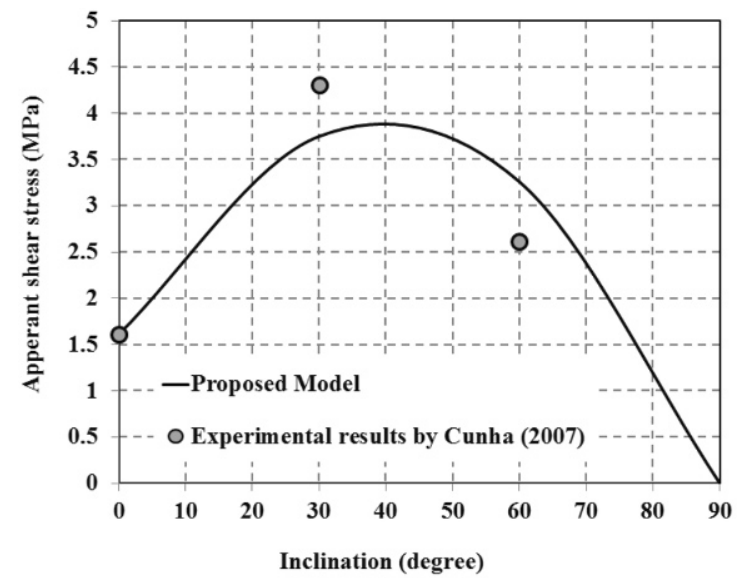

(b) $l_{b}=10 \mathrm{~mm}$, hooked fiber

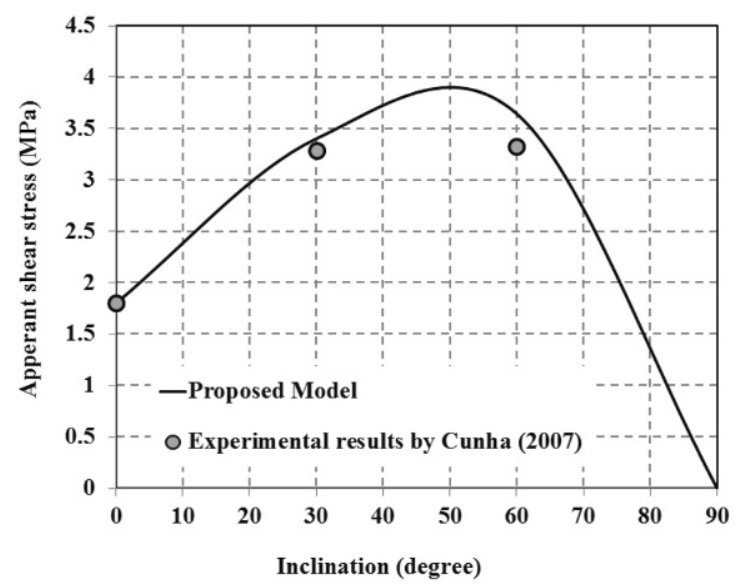

(c) $l_{b}=20 \mathrm{~mm}$, hooked fiber

Figure 9. Comparison of the proposed apparent shear strengths (Equation (7)) with shear strengths obtained by using the Cunha [29] experimental results subjected to calibration according to inclination angle by using Equations (2)-(11) in Figure 2.

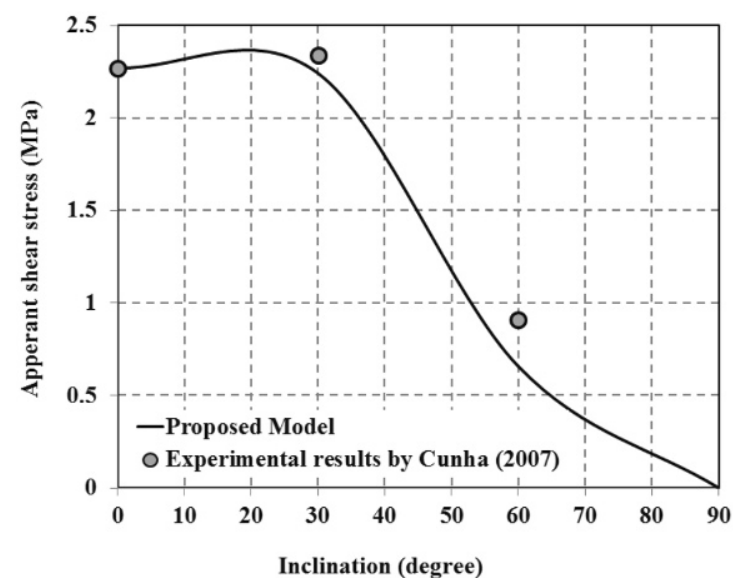

(a) $l_{b}=30 \mathrm{~mm}$, smooth fiber

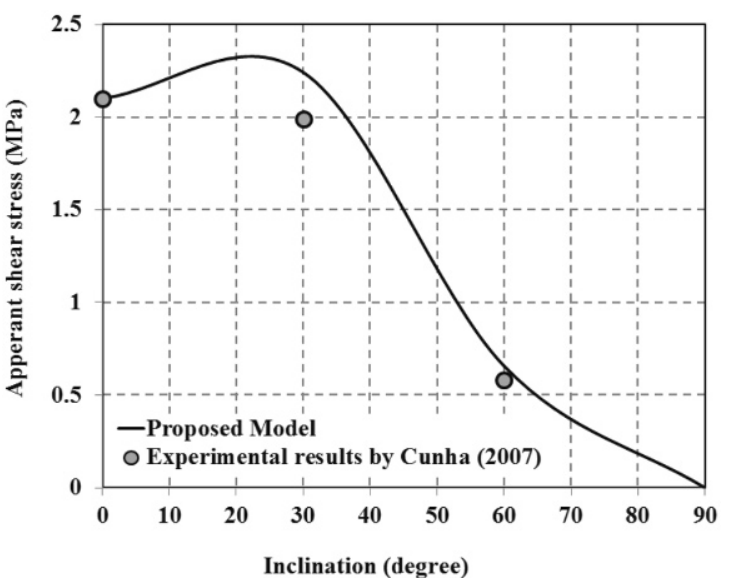

(b) $l_{b}=30 \mathrm{~mm}$, hooked fiber

Figure 10. Comparison of the proposed apparent shear strengths (Equation (8)) with shear strengths obtained by using the Cunha [29] experimental results subjected to calibration according to inclination angle by using Equation (2)-(11) in Figure 2. 


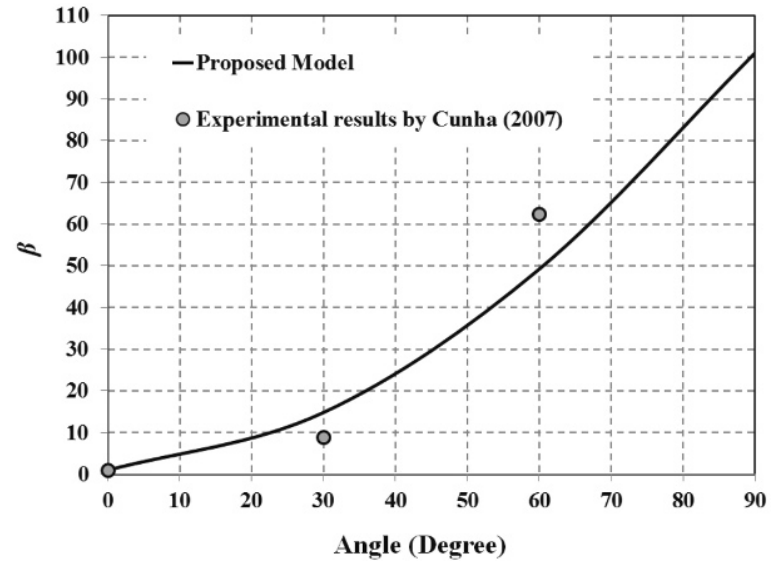

Accordingly, the pullout behavior of inclined fiber can be expressed in three stages and are shown in Figures 1-3. Equations (11) and (12) represent the stage 1 when fiber completely bonded along the length of the fiber. While Equations (13) to (16) represent stage 2, when fiber partially bonded along its embedded length and finally Equations (17) to (19) correspond to behavior in stage 3 when fiber completely debonded over its embedded length. Apparent shear strengths that reflect the effects of fiber inclination angle, such as snubbing and matrix spalling effects, on both load and slip displacement are adopted in the pulling out procedure.

Figure 11. Comparison of the predicted curve for $\beta$ by Equation (10) with the experimentally obtained $U_{\text {peak }}(\varphi) / U_{\text {peak }}(0)$ ratios for different inclination angles.

Stage 1 - fiber completely bonded along the length of the fiber:

$$
\begin{gathered}
\sigma_{\max }=\sigma_{d}(\phi)=\frac{-2 \tau_{\max (a p p)}(\phi)(\gamma+\alpha-\gamma \eta \alpha+\alpha \eta)}{a \beta}\left[\frac{(\alpha-\gamma \eta \alpha+\alpha \eta) \cosh (\beta L)}{\sinh (\beta L)}\right]^{-1} \\
\left(\sigma_{\max } / U_{b}\right)(\phi)=\frac{[((\alpha-\gamma \eta \alpha+\alpha \eta) \cosh (\beta L)) / \sinh (\beta L)]^{-1}}{E_{f} \alpha \beta[\{((\alpha-\gamma \eta \alpha+\alpha \eta) \cosh (\beta L)) / \sinh (\beta L)\}+\gamma L]}
\end{gathered}
$$

Stage 2 - fiber partially bonded along its embedded length:

Bond and frictional components of pullout stress:

$$
\begin{aligned}
\sigma_{0}(\phi) & =\sigma_{0, \text { bond }}(\phi)+\sigma_{0, \text { fric }}(\phi) \\
\sigma_{0, \text { bond }}(\phi) & =\sigma_{d}(\phi) \\
\sigma_{0, \text { fric }}(\phi) & =\left[e^{\frac{-2 \mu w l_{d}}{a}}-1\right] \sigma_{d}(\phi)+\frac{\sigma_{c}}{w}\left[e^{\frac{-2 \mu w l_{d}}{a}}-1\right]
\end{aligned}
$$

The total fiber displacement:

$$
\begin{aligned}
U_{p d}(\phi)= & \frac{\sigma_{d}(\phi)}{E_{f}(\gamma+\alpha-\gamma \eta \alpha+\alpha \eta)}\left[(\alpha-\gamma \eta \alpha+\alpha \eta-\gamma) \frac{\cosh \left[\beta\left(L-l_{d}\right)\right]-1}{\beta \sinh \left[\beta\left[L-l_{d}\right]\right]}+\gamma\left(L-l_{d}\right)\right] \\
& -\frac{\sigma_{c} l_{d}}{E_{f} w}-\frac{\sigma_{c} l_{d}}{E_{f} w}-\frac{a}{2 E_{f} \mu w}\left[\sigma_{d}(\phi)+\frac{\sigma_{c}}{w}\right]\left[e^{\frac{-2 \mu w l_{d}}{a}}-1\right]
\end{aligned}
$$

Stage 3 - fiber completely debonded over its embedded length and pulling out: Interfacial frictional shear stress distribution

$$
\tau_{f}(\phi)=\mu \sigma_{c}(\phi) e^{\frac{-2 w \mu z}{a}} \quad 0 \leq z \leq L-p_{d}
$$

Fiber pullout stress:

Fiber displacement:

$$
\sigma_{0}(\phi)=\frac{-\sigma_{c}(\phi)}{w}\left[1-e^{\frac{-2 w \mu\left(L-p_{d}\right)}{a}}\right]
$$

$$
U_{p d}(\phi)=p_{d}-\frac{\sigma_{c}(\phi)}{E_{f} w}\left[\left(L-P_{d}\right)+\frac{a}{2 \mu w}\left\{e^{\frac{-2 \mu w\left(L-p_{d}\right)}{a}}-1\right\}+p_{d}\left\{1-e \frac{-2 \mu w\left(L-p^{d}\right)}{a}\right\}\right]
$$




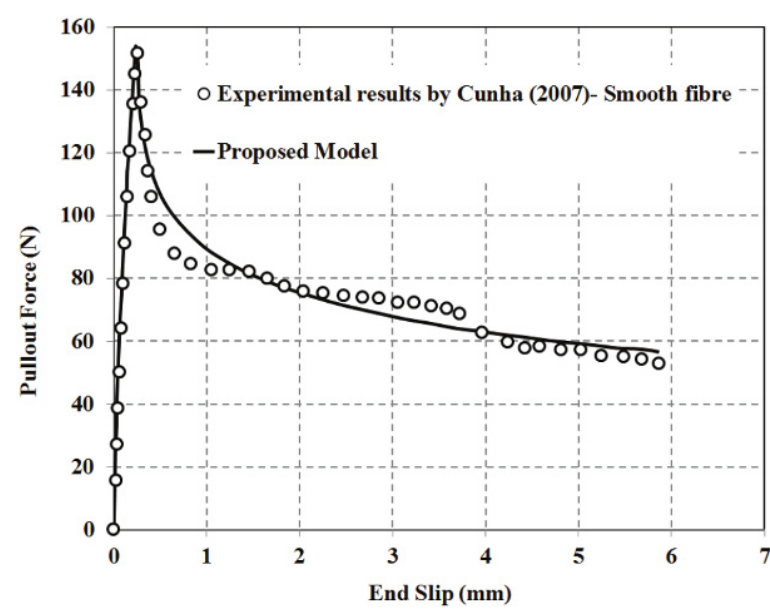

(a) $l_{b}=30 \mathrm{~mm}$

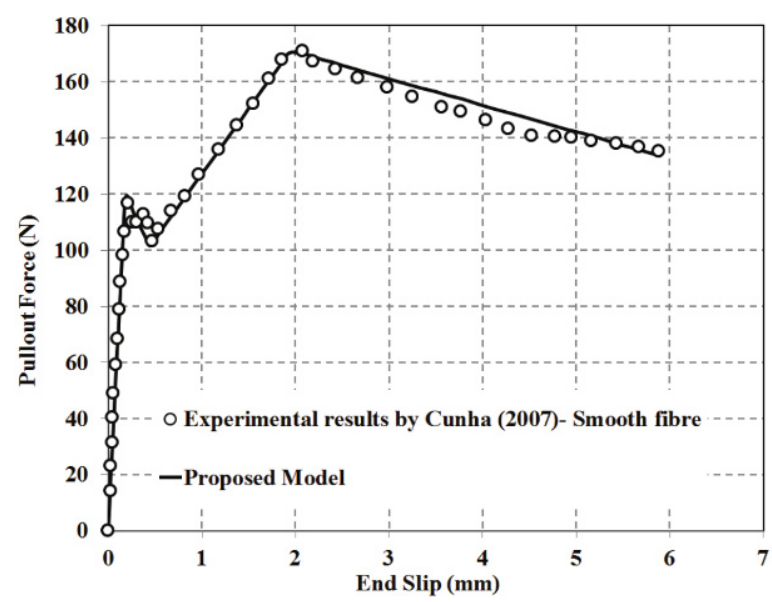

(c) $l_{b}=20 \mathrm{~mm}$, inclination angle $\left(60^{\circ}\right.$

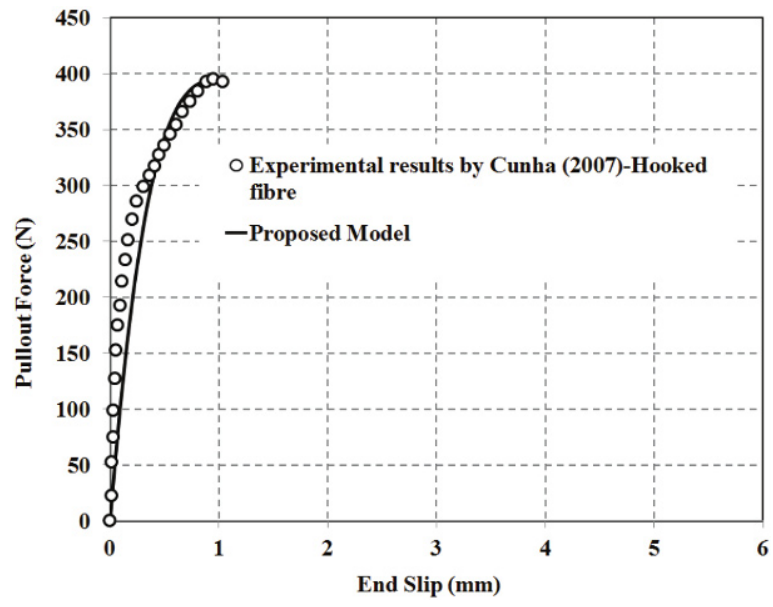

(e) $l_{b}=20 \mathrm{~mm}$, inclination angle $\left(30^{\circ}\right.$

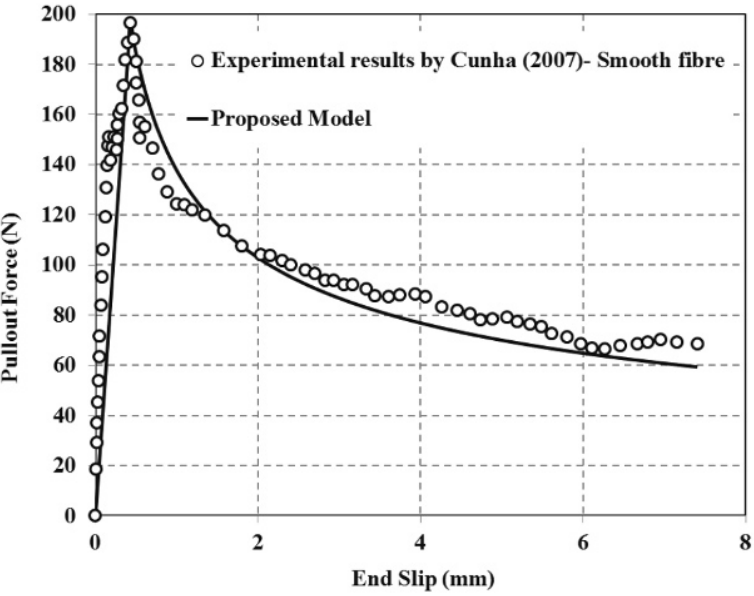

(b) $l_{b}=30 \mathrm{~mm}$, inclination angle $\left(30^{\circ}\right)$

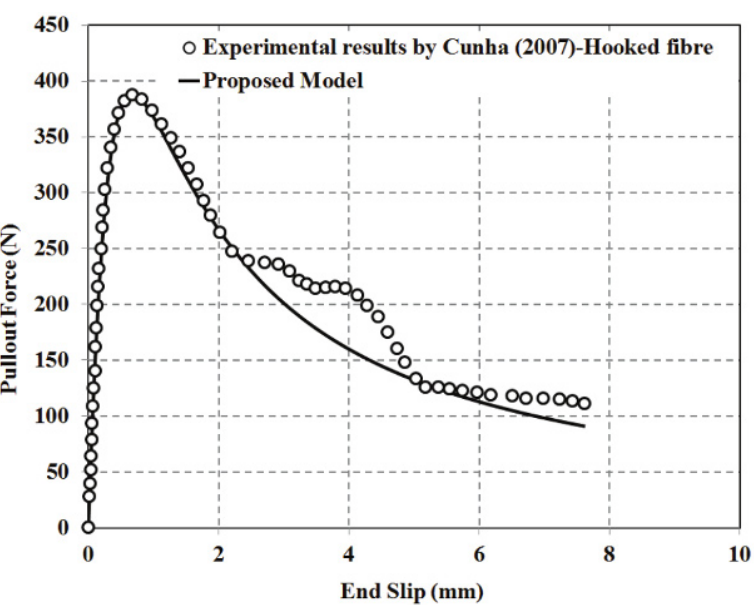

(d) $l_{b}=30 \mathrm{~mm}$

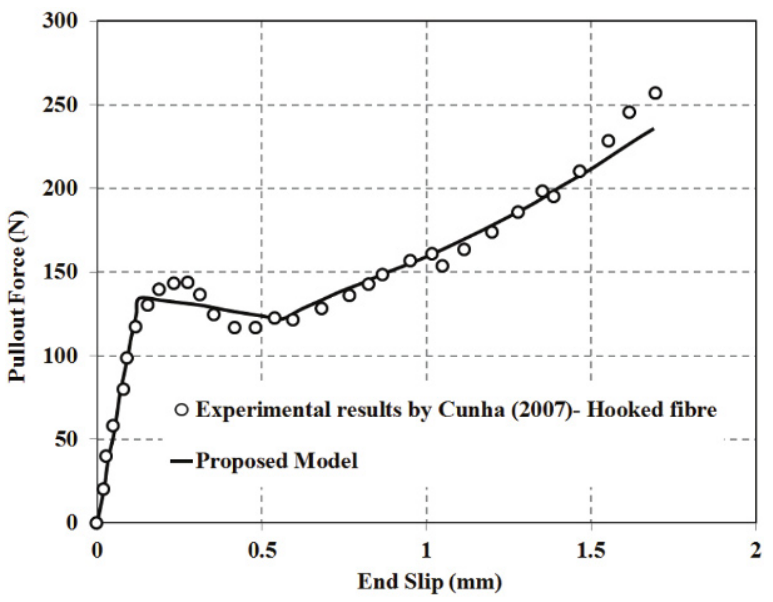

(f) $l_{b}=20 \mathrm{~mm}$, inclination angle $\left(60^{\circ}\right.$

Figure 12. Comparison of the experimentally obtained load-slip curves (Cunha [29]) versus the predicted curves by using the proposed model. 
Table 9. Summary of the influence of the addition of hooked-end steel fibers on the bond behavior.

\begin{tabular}{lcccccc}
\hline References & \multicolumn{3}{c}{ splitting failure } & \multicolumn{3}{c}{ pull-out failure } \\
\cline { 2 - 7 } & STR & STF & DUC & STR & STF & DUC \\
\hline \hline Hartwich [63] & ++ & 0 & ++ & 0 & 0 & ++ \\
Samen Ezeldin & ++ & 0 & + & 0 & na & + \\
\& Balaguru [64] & & & & & & \\
Harajli [62] & na & na & na & + & + & + \\
Soroushian et al. [24] & na & na & na & + & + & + \\
Harajli et al. [61] & 0 & na & + & na & na & na \\
Hota \& Naaman [65] & + & 0 & + & na & na & na \\
Plizzari [66] & + & + & + & + & na & + \\
De Bonte [67] & 0 & 0 & + & + & 0 & 0 \\
Literature survey & + & nc & + & nc & nc & nc \\
Bigaj-van Vliet [26] & & & & & & \\
(summary of the above) & & & & & & \\
Dupont et al. [68] & na & 0 & + & + & 0 & + \\
Plizzari et al. [69] & + & na & + & na & na & na \\
Weiße NSC [70] & 0 & 0 & + & 0 & 0 & 0 \\
Weiße HSC [70] & + & 0 & ++ & na & na & na \\
Pfyl [71] & na & na & na & na & + & na \\
\hline
\end{tabular}

\section{Modeling of bond deformed re- inforcing steel bars embedded in SFRSCC}

\subsection{Analytical models database for bond of reinforcing steel bars embedded in the conven- tional concrete (CC) and SCC}

From recent studies of Aslani and Nejadi [47, 48], in the literature, there are several analytical and numerical models that attempt to represent the bond stress response in the steel-concrete interface. Most of these models are based on results of experiments that investigated the concrete compressive strength, concrete cover (C), steel bar diameter, and embedment length. In these studies, empirical equations of Orangun et al. [49], Kemp and Wilhelm[50], Kemp [51], Chapman and Shah [52], Harajli [53], Pillai et al. [54], and Bae [55] that represent the bond behavior are compared with experimental results database.

Aslani and Nejadi [48] reported that available bond strength prediction models [49-51, 53, 55, 57] generally underestimate the bond strength for both SCC and CC mixtures when compared to experimental results. Although, Chapman and Shah [52] have a more accurate prediction equation, the model tends to underestimate the bond strength.

In the analysis of reinforced concrete structures, the bond action between steel bars and concrete is often viewed as a bond-slip relationship. This relationship expresses the local bond stress at any location along a bar as a function of the local slip. Numerous bond-slip relationships have been proposed and formulated. However, given that bond-slip relationships are impacted by various factors [56] that vary across bond tests, these proposed models are different [57]. For example, in pullout tests, bond-slip relationships obtained from extremely short specimens are different from those obtained from longer ones. Even in the same specimen, the bond-slip relationship varies with the location along the bar if the free end slip exists.

From recent studies of Aslani and Nejadi [47, 48] available bond stress-slip prediction models [59-61] are compared with available experimental results database. Based on the achieved results, available bond-slip models are not appropriate for both CC and SCC bond strength prediction. However, the Huang et al. [60] model has good trend for prediction of bond strength and this model should be modified based on the experimental conditions.

Figure 12 compares the Cunha [29] load-slip curves from the experiment with the predicted curves obtained from the proposed model using $\tau_{\max (a p p)}, \tau_{f(a p p)}$ and $\beta$ with different fiber inclination angles.

\subsection{Analytical models database for bond of deformed reinforcing steel bars embedded in SFRC}

A thorough survey of existing literature about the bond of ribbed reinforcing steel bars embedded in SFRC was carried out by Bigaj-van Vliet [26]. For pull-out tests with a short embedment length she summarized existing literature on the effect of fiber volume, bar diameter, concrete cover thickness, fiber shape, bar position, bar geometry, matrix strength, embedment length, confinement on bond strength, bond stiffness, bond ductility and failure propagation, and structural response. For tensile element tests, evidences were summarized with regard to the effect of fiber volume, fiber shape, matrix strength on the tension stiffening effect, failure propagation, and structural response. For beam tests, the results of Harajli [62] on the effect of specimen type on bond ductility were reviewed. Noghabai [25] re-ported about tests on thick-walled concrete rings, tie elements and beams on normal and high strength concretes with four types of steel fibers. Table 9 shows the effect of the addition of hooked end steel wire fibers to conventional concrete on the bond strength (STR), bond stiffness (STF) and bond ductility (DUC) in the case of splitting or pullout failure $[24,26,61-71]$. The following symbols will be used to indicate the tendencies the researchers found for an increased fiber volume fraction for the parameters they investigated:

- ++ significantly increased

- + increased 
- 0 no pronounced difference

- nc no clear agreement

- na not available

It is noted that the specimen geometry and way of manufacturing were different or often not well re-ported in the literature and that these factors play an important role for fiber distribution and fiber orientation and thus for the tensile properties of the concrete. The existing studies on the effect of hooked-end steel fibers on the bond behavior of ribbed bars in concrete are hardly comparable due to variations in mechanical and geometrical bar, steel fiber and concrete matrix properties and partly reported contradictory results. Therefore, it was decided to systematically investigate the influence of the addition of different kinds and amounts of steel fibers on the local bond behavior of ribbed bars in SCC [30].

\subsection{Proposed analytical model for bond of deformed reinforcing steel bars embedded in SFRSCC}

Many researchers have examined relationships be-tween pull-out load and compressive strength. All studies in this area have shown that the bond strength (stress) increases with the compressive strength of concrete. In this regard, $\mathrm{ACl} 318$ [72] proposes that the bond strength is linearly proportional to $\left(f_{c}^{\prime}\right)^{0.5}$. It can be easily concluded from the earlier literature that the average bond stress reduces as the embedment length increases due to the non-linear stress distribution that exists between the rebar and the concrete. Another conclusion is that average bond stress decreases with larger rebar diameters. Different explanations exist for the decrease in bond stress due to the larger rebar diameters. In this study, the relationships proposed for the CC and SCC are based on regression analyses using existing experimental data, with the results expressed as Equation (20).

$$
\tau_{\max }=\left(0.672\left(\frac{c}{d_{b}}\right)^{0.6}+4.8\left(\frac{d_{b}}{l_{d}}\right)\right)\left(f_{c}^{\prime}\right)^{0.55}
$$

Based on the trend of the analytical results, supported with available experimental data, the following Equation (21) is proposed to describe the increase in bond strength due to the presence of steel fiber reinforcement, applicable for both HSCC and NSCC:

$$
\tau_{f r}=2.25\left(V_{f} l_{f} / d_{f}\right) \times\left(c / d_{b}\right)\left(f_{c}^{\prime}\right)^{0.50}
$$

Proposed bond-slip relationship of normal strength SCC without steel fiber inside as Equations (22)-(24):

$$
\begin{aligned}
& \tau_{c}=\left(\tau_{\max }\right) s_{c} \quad s_{c}<s * \\
& \tau_{c}=\left(\tau_{\max }\right) s_{c} \quad s_{c}<s * \text { to } 2.5 s * \\
& \tau_{c}=\left(\tau_{\max }\right) e^{-0.221 s *} \quad s_{c}<2.5 s *
\end{aligned}
$$

where $s *$ is the corresponding slip to the $0.85 \tau_{\max }$ and $S_{c}$ is the slip in general. Proposed bond-slip relationship of normal strength SCC with steel fiber inside as Equations (25) to (27):

$$
\begin{aligned}
& \tau_{c}=\left(\tau_{\max }+\tau_{f r}\right) s_{c} \quad s_{c}<s^{*} \\
& \tau_{c}=\left(\tau_{\max }+\tau_{f r}\right) \quad s_{c}=s^{*} \text { to } 2.75 s^{*} \\
& \tau_{c}=\left(\tau_{\max }+\tau_{f r}\right) e^{-0.210 s^{*}} \quad s_{c}>2.75 s^{*}
\end{aligned}
$$

Proposed bond-slip relationship of high strength SCC without steel fiber inside as Equations (28) to (29):

$$
\begin{aligned}
& \tau_{c}=\left(\tau_{\max }\right) s_{c} \quad s_{c}<s^{*} \\
& \tau_{c}=\left(\tau_{\max }\right) e^{-0.135 s^{*}} \quad s_{c} \geq s^{*}
\end{aligned}
$$

Proposed bond-slip relationship of high strength SCC with steel fiber inside as Equations (30) to ((31):

$$
\begin{aligned}
& \tau_{c}=\left(\tau_{\max }+\tau_{f r}\right) s_{c} \quad s_{c}<s^{*} \\
& \tau_{c}=\left(\tau_{\max }+\tau_{f r}\right) e^{-0.005 s^{*}} \quad s_{c} \geq s^{*}
\end{aligned}
$$

Figures 13 to 17 show comparisons of the experimentally obtained Bond-slip curves (Schumacher [30]) versus the predicted curves by using the proposed models.

\section{Results and discussions}

In this study, Dubey model are used to overcome pervious inadequacies of the existing fiber pullout models. In this study, the evolution of the interfacial coefficient of friction during the process of fiber pullout that is included in this model is calibrated for SFRSCC (see Table 5). Also, for the effect of fiber inclination angle is included in this model and this model is calibrated by using available experimental results. As shown in Figures 4-7 the proposed models for coefficient of friction versus pullout displacement by allowing for the type of fibers (smooth and hooked) and compressive strength of SCC (normal and high strength) are in good agreement with the experimental results. By utilizing the proposed models for the coefficient of friction in Dubey [22] pullout model for 


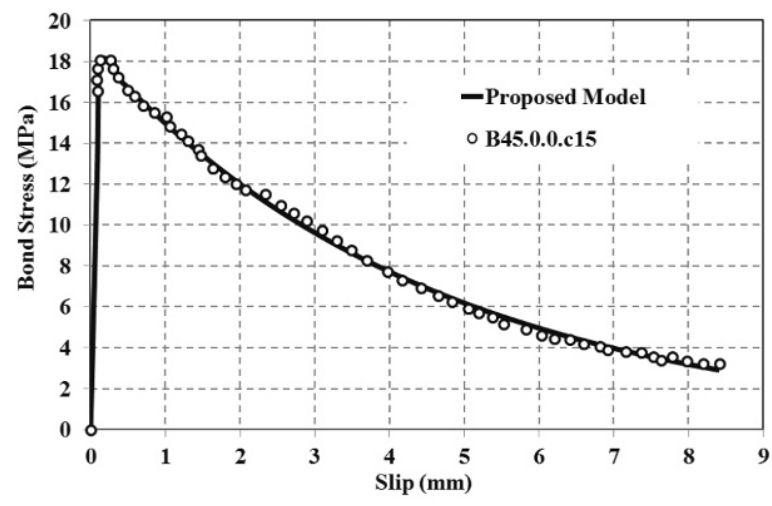

(a)

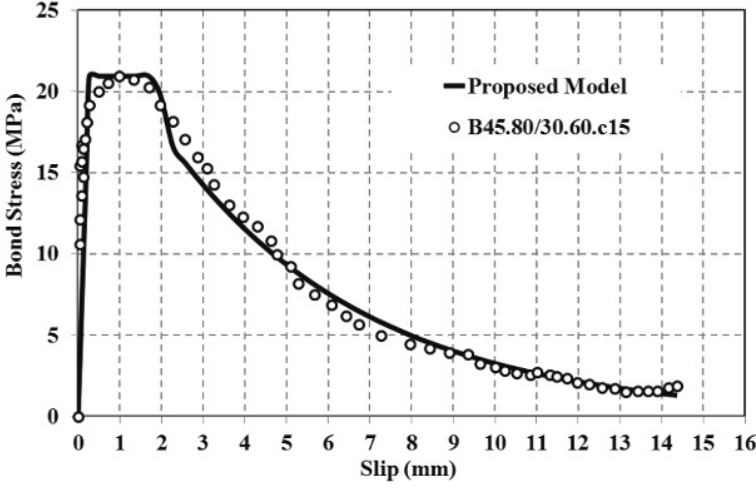

(b)

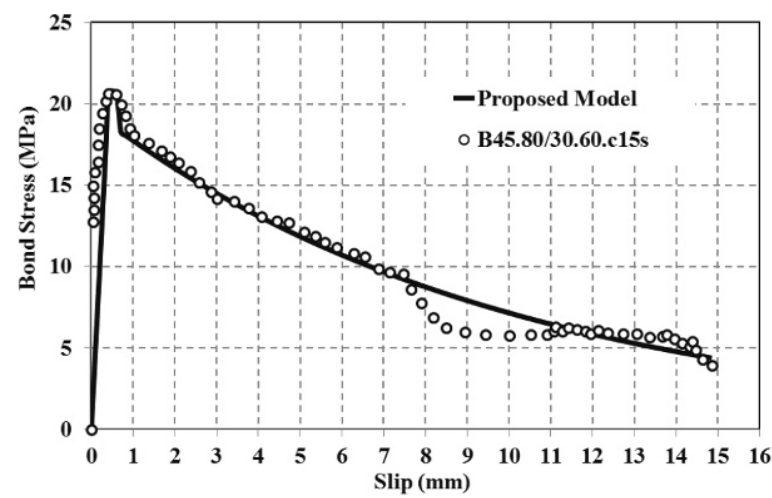

(c)

Figure 13. Comparison of the experimentally obtained load-slip curves (Schumacher [30]) versus the predicted curves by using the proposed model for (a) $f_{c}^{\prime}=45$, without fiber and concrete cover $=15$, (b) $f_{c}^{\prime}=45$, with fiber aspect ratio: $80 / 30$ " and fiber content: 60 (kg/m $\left.{ }^{3}\right)$ ", and concrete cover $=15$, and (c) $f_{c}^{\prime}=45$, with fiber "aspect ratio: $45 / 30$ " and "fiber content: $60\left(\mathrm{~kg} / \mathrm{m}^{3}\right)$ ", and concrete cover $=15$ sawn cast.

aligned fiber, this model demonstrates a good capability in predicting the pullout behavior of SFRSCC. Table 6 presents comparison of the obtained Grünewald [27] peak pullout force versus the predicted peak pullout force using the modified pullout model. This modified model shows a good capability when considering different fiber types and compressive strength for SCC. Also, Figure 8 compares the Holschemacher and Klug [28] experimental load-slip curves with the predicted curves obtained by using the proposed model for the different types of fiber (smooth and short-hooked or long-hooked) which proves a good prediction. In the Figure 8(a) and 8(c), there are a discrepancy in the post-peak part of pullout force versus end slip curves, that make differences between proposed model prediction with the experimental results. These discrepancies are related to test condition and sudden pullout of fibre from the matrix.

Figures 9-10 illustrate the proposed $\tau_{a p p}$ models when allowing for the different types of fiber and embedment fiber lengths which demonstrate a good agreement with the experimental results. By using the proposed $\tau_{a p p}$ and $\beta$ in the proposed pullout model for inclined fibers which are presented in Equations (11) to (19), show a good prediction capability for the pullout behavior of SFRSCC. Furthermore, Figure 12 shows that the proposed model has a good agreement with the experimental results in different inclination angles too.

Furthermore, Figures 13 to 17 show that the proposed models for bond of deformed reinforcing steel bars embedded in SFRSCC have a good agreement with the experimental results with different strength of SFRSCC, with different fiber volume, and with different concrete cover. For SCC without fibers, Weiße [70] showed that the direction of casting the pullout test specimens does not significantly influence the bond stress-slip relationship. For SFRSCC, however, the direction of casting may influence the fiber orientation and distribution and therefore the pullout behavior. To get an impression of the fiber distribution in the Schumacher [30] tests, the specimens with fibers were sawn open after testing and the number of fibers in an area of $15 \times 30 \mathrm{~mm}$ next 


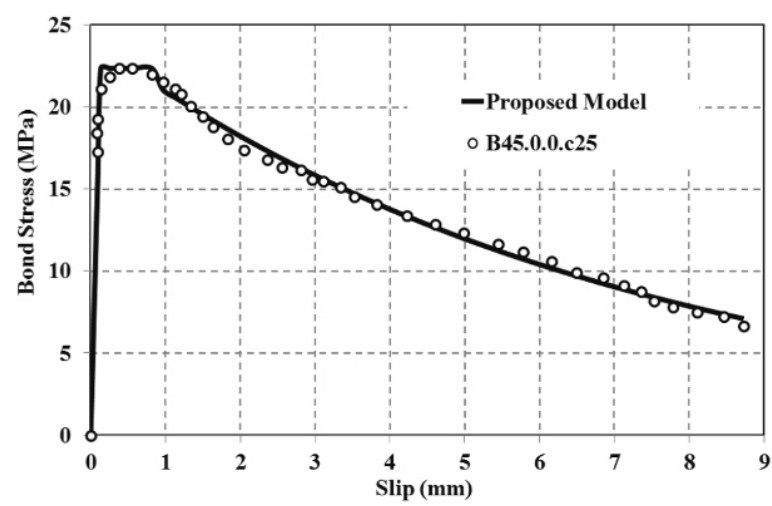

(a)

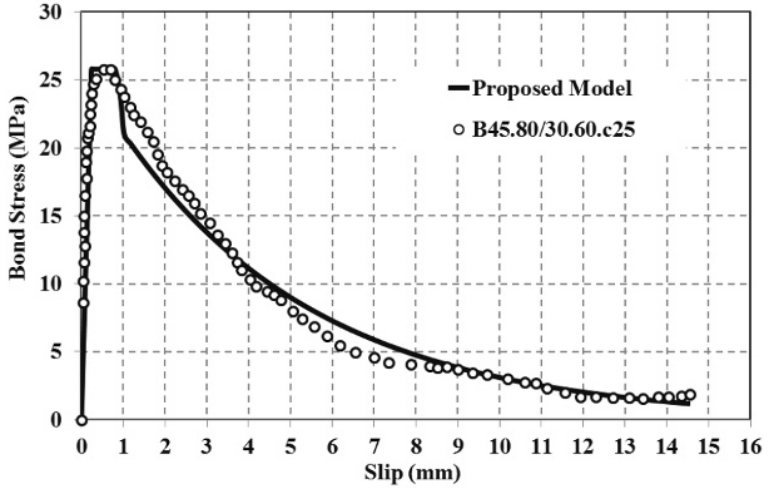

(b)

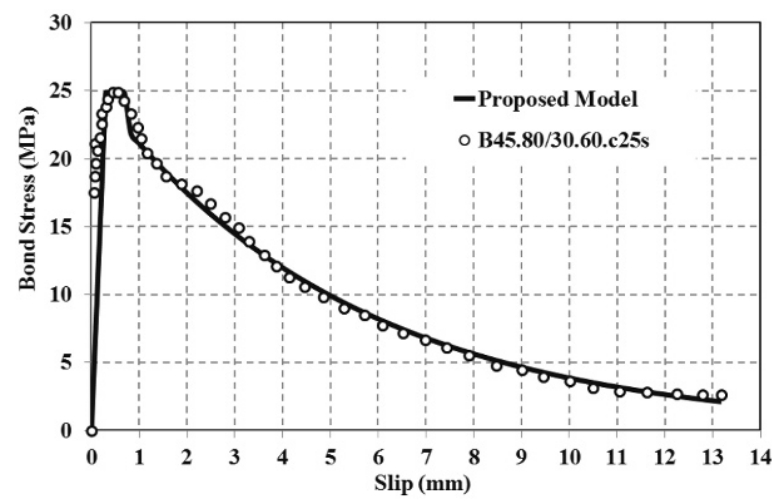

(c)

Figure 14. Comparison of the experimentally obtained load-slip curves (Schumacher [30]) versus the predicted curves by using the proposed model for (a) $f_{c}^{\prime}=45$, without fiber and concrete cover $=25$, (b) $f_{c}^{\prime}=45$, with fiber "aspect ratio: $80 / 30$ " and "fiber content: 60 (kg/m $\left.{ }^{3}\right)$ ", and concrete cover $=25$, and $(c) f_{c}^{\prime}=45$, with fiber "aspect ratio: $45 / 30$ " and "fiber content: $60\left(\mathrm{~kg} / \mathrm{m}^{3}\right)$ ", and concrete cover $=25$ sawn cast.

to the reinforcing bar was counted manually at both sides of the bar. Remarkably, no significant difference between the sawn and the cast specimen was observed. Therefore, the values for the sawn and cast specimens were averaged. The addition of steel fibers slightly influences the bond behavior in case of pullout bond failure and is expected to have a pronounced effect in case of splitting bond failure

\section{Conclusion}

Bond steel fiber and matrix made of SCC:

- the proposed models for coefficient of friction versus pullout displacement by allowing for the different types of fiber and strength for steel fiber reinforced self-compacting concrete (normal and high) demonstrate a good agreement with the experimental results. However, the observed decrease in coefficient of friction could be due to the matrix wear and con- sequent smoothening of the interface layer as the fiber pulls out of the matrix;

- Dubey [22] pullout model for aligned fiber is used by calibrating it with the proposed coefficient of friction for steel fiber reinforced self-compacting concrete. This calibrated and modified model reveals good results for the different types of fiber (smooth and hooked) and strength for self-compacting concrete (normal and high);

- In order to take into account the effects of the fiber inclination in the pullout model, apparent shear strengths $\left(\tau_{(a p p)}\right)$ and slip coefficient $(\beta)$ are introduced to express the variation of the pullout peak load and the augmentation of peak slip when the inclination angle increases. They are expressed as functions of the inclination angle $(\phi)$;

- the proposed pullout model for inclined fibers by utilizing the proposed apparent shear strengths and 


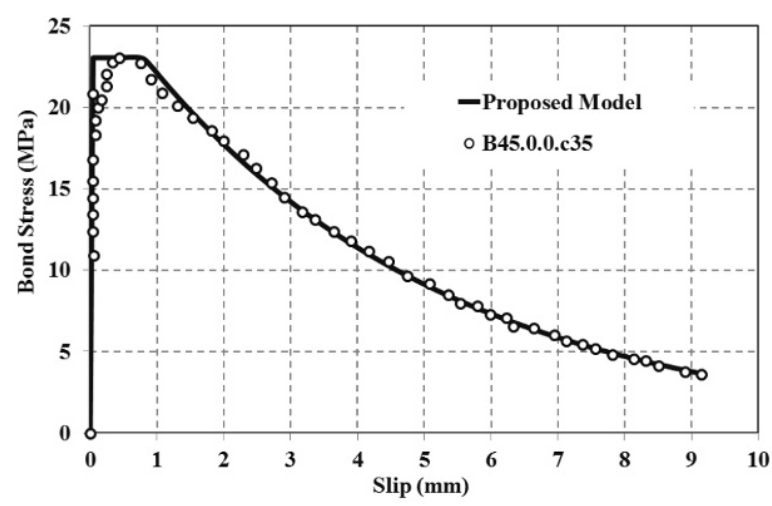

(a)

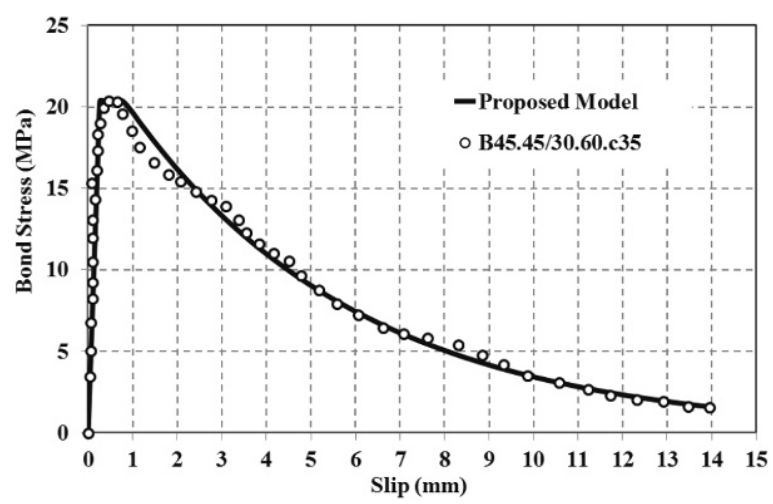

(c)

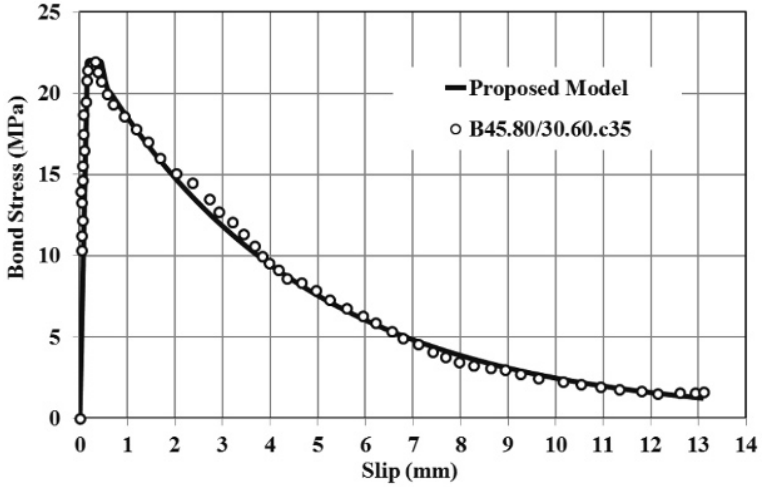

(b)

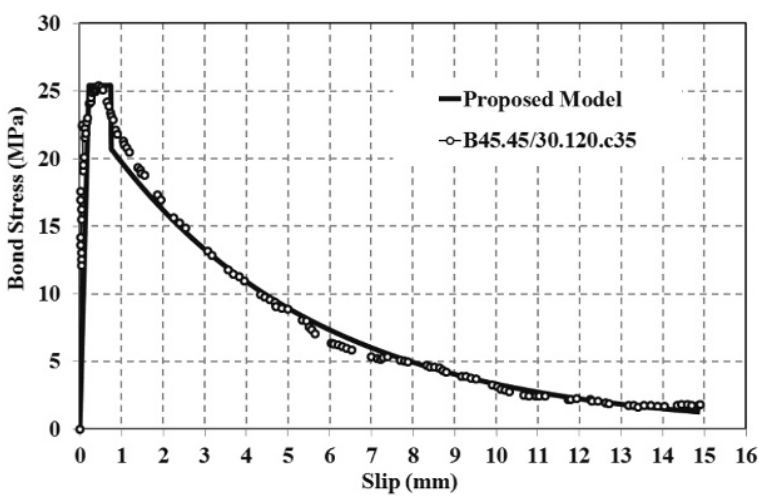

(d)

Figure 15. Comparison of the experimentally obtained load-slip curves (Schumacher [30]) versus the predicted curves by using the proposed model for (a) $f_{c}^{\prime}=45$, without fiber and concrete cover $=35$, (b) $f_{c}^{\prime}=45$, with fiber "aspect ratio: $80 / 30$ " and "fiber content: $60\left(\mathrm{~kg} / \mathrm{m}^{3}\right)$ ", and concrete cover $=35$, (c) $f_{c}^{\prime}=45$, with fiber "aspect ratio: $45 / 30$ " and "fiber content: $60\left(\mathrm{~kg} / \mathrm{m}^{3}\right)$ ", and concrete cover $=35$, and (d) $f_{c}^{\prime}=45$, with fiber "aspect ratio: 45/30" and "fiber content: $120\left(\mathrm{~kg} / \mathrm{m}^{3}\right)$ ", and concrete cover $=35$.

slip coefficient simulates the experimental pullout load-slip curves accurately for both hooked and straight aligned fibers with different embedment lengths.

Bond deformed reinforcing steel bars embedded in SFRSCC

- the proposed pullout models are simple, rational, and general. The proposed models are covered bond of deformed reinforcing steel bars embedded in SCC and SFRSCC. The results predicted by the model were in very good agreement with experimental results for both NSCC and HSCC, without and with different fiber volume reinforcement;

- proposed models for the bond of deformed reinforcing steel bars embedded in SFRSCC are simple, rational and accurate.

\section{Notations}

a: $\quad$ fiber radius

$b$ : $\quad$ outer radius of the matrix coaxial cylinder in a pullout test geometry

$c$ : rate at which the interfacial coefficient of friction decays with increase in $p_{d}$

$E_{m}$ : matrix elastic modulus

$E_{f}$ : fibre elastic modulus

$f$ : $\quad$ snubbing friction coefficient

$L: \quad$ embedded fiber length in a pullout specimen

$r$ : radial direction in a pullout specimen

$z$ : axial fiber direction in a pullout specimen

$\beta$ : $\quad$ slip coefficient

$\phi$ : $\quad$ fiber inclined angle

$\sigma_{0}$ : fiber pullout stress

$\sigma_{f}: \quad$ fiber axial stress

$\sigma_{m}: \quad$ matrix axial stress

$\sigma_{a}$ : matrix axial stress at the interface (i.e., $r=a$ )

$\sigma_{0, \text { bond }}$ : bond component of pullout stress

$\sigma_{0, \text { fric }}$ : frictional component of pullout stress 


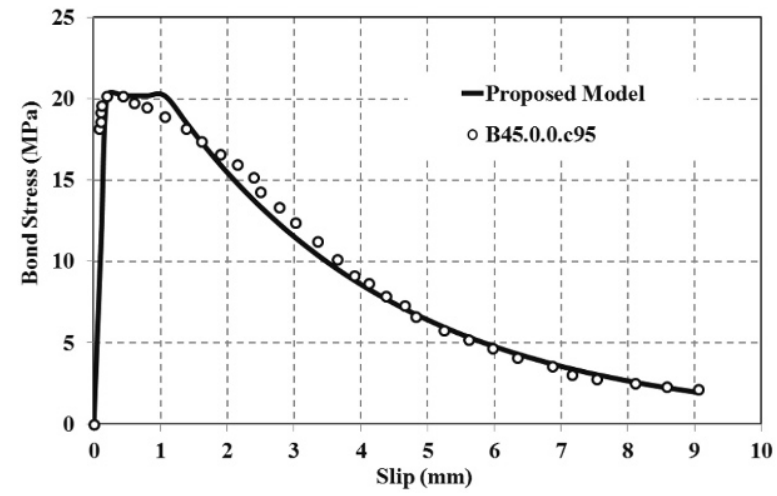

(a)

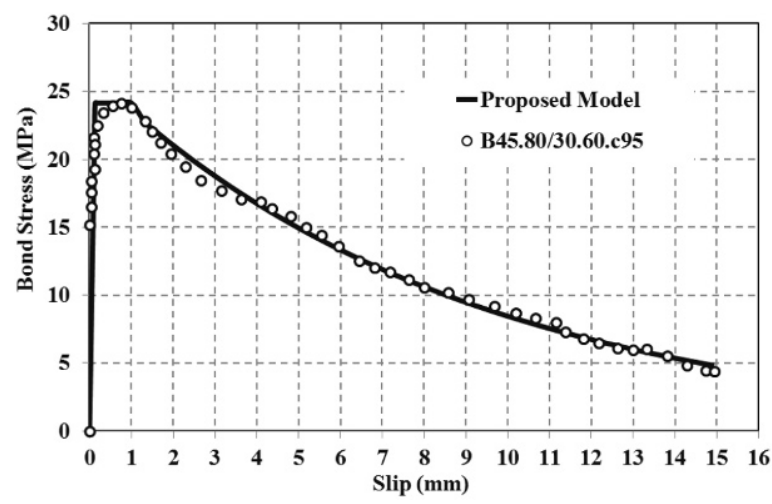

(b)

Figure 16. Comparison of the experimentally obtained load-slip curves (Schumacher [30]) versus the predicted curves by using the proposed model for (a) $f_{c}^{\prime}=45$, without fiber and concrete cover $=95$ and (b) $f_{c}^{\prime}=45$, with fiber "aspect ratio: $80 / 30$ " and "fiber content: $60\left(\mathrm{~kg} / \mathrm{m}^{3}\right)$ ", and concrete cover $=95$.

$\sigma_{0, \text { peak }}$ : fiber peak pullout stress

$\sigma_{b}$ : matrix stress at the surface of coaxial cylinder (i.e., at $r=b$ )

$\sigma_{c}$ : contact stress at the fiber-matrix interface

$\sigma_{c p}: \quad$ contact stress at fiber-matrix interface after Poisson's contraction of fiber

$\sigma_{d}$ : fiber debonding stress

$\tau_{m}$ : matrix shear stress

$\tau_{a}: \quad$ interfacial shear stress

$\tau_{s}$ : fiber-matrix interfacial shear strength

$\tau_{f}$ : interfacial shear stress over the debonded interface

$\tau_{(\text {app })}:$ apparent bond strength

$\delta_{r}$ : fiber-matrix misfit

$\mu$ : interfacial coefficient of friction

$\mu_{t}$ : initial value of the interfacial coefficient of friction

$\mu_{s s}$ : $\quad$ steady-state value of the interfacial coefficient of friction

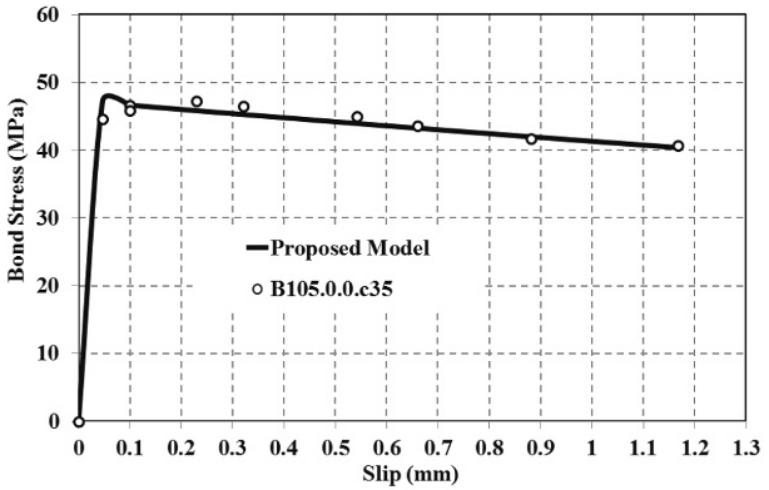

(a)

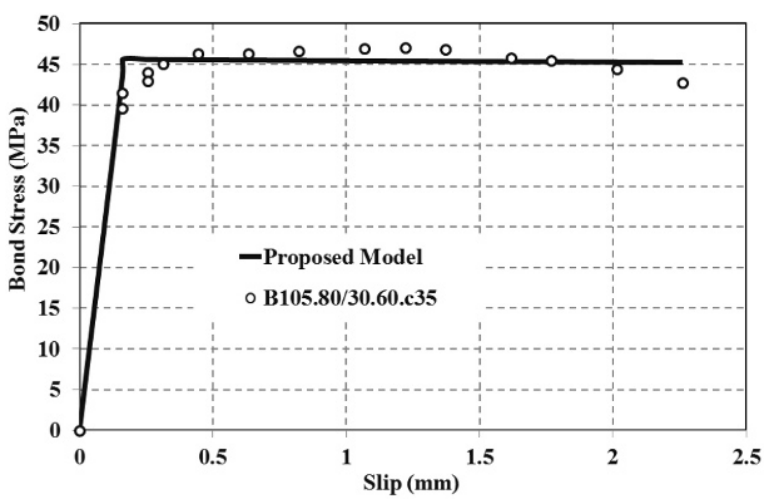

(b)

Figure 17. Comparison of the experimentally obtained load-slip curves (Schumacher [30]) versus the predicted curves by using the proposed model for (a) $f_{c}^{\prime}=105$, without fiber and concrete cover $=35$ and (b) $f_{c}^{\prime}=105$, with fiber "aspect ratio: 80/30" and "fiber content: $60\left(\mathrm{~kg} / \mathrm{m}^{3}\right)$ ", and concrete cover $=35$.

$l_{d}: \quad$ interfacial debond length

$l_{d, \text { cat }}$ : catastrophic debond length of interface

$p_{d}$ : rigid body displacement of fiber in a pullout test

$p_{d 1}$ : $\quad$ rigid body displacement of the fiber in a pullout test

$p_{d 2}$ : rigid body displacement of the fiber in a pullout test

$P_{p_{d 1}}$ : pullout load corresponding to the pullout distance, $p_{d 1}$

$P_{p_{d 2}}$ : pullout load corresponding to the pullout distance, $p_{d 2}$

$P_{m}$ : $\quad$ measured pullout load from the pullout test

$U_{b}$ : fiber displacement when fiber is completely bonded

$U_{p d}$ : fiber displacement during partial interfacial debonding

$U_{p_{\text {d,peak }}}$ : fiber displacement corresponding to peak pullout load 
$v_{m}$ : Poisson's ratio of matrix material

$v_{f}$ : Poisson's ratio of fiber material

$w_{m}$ : matrix axial displacement

$w_{a}$ : matrix displacement at the interface

(i.e., $r=a$ )

$w_{b}$ : matrix displacement at the surface of coaxial cylinder (i.e., at $r=b$ )

$W_{p}$ : Work of fiber pullout when the rigid body displacement of the fiber increases from $p_{d 1}$ to $p_{d 2}$

\section{References}

[1] ACl Committee 544. State-of-the-Art Report on Fiber Reinforced Concrete - ACl 544.1R-96 (Reapproved 2002), ACI Manual of Concrete Practice, Part 6, 2008, ACI544.1R-7 - ACI544.1R-24, 2008

[2] Mandel J., Wei S., Said S., Studies of the properties of the fiber-matrix interface in steel fiber reinforced mortar, ACI Mater. J., 84(2), 1987, 101-109

[3] Stang H., Shah S.P., Failure of fiber-reinforced composites by pull-out fracture, J. Mater. Sci., 21(3), 1986, 953-957

[4] Armelin H.S., Banthia N., Predicting the flexural post cracking performance of steel fiber reinforced concrete from the pullout of single fibers. ACI Mater. J., 94(1), 1997, 18-31

[5] Li V.C., Wu C., Wang S., Ogawa A., et al., Interface tailoring for strain-hardening polyvinyl alcoholengineered cementitious composites (PVA-ECC), ACI Mater. J., 99(5), 2002, 463-472

[6] Lee Y., Kang S.-T., Kim J.-K., Pull-out behavior of inclined steel fiber in an ultra-high strength cementitious matrix, Constr. Build. Mater., 24, 2010, 2030 2041

[7] Chanvillard G., Aïtcin P.C., Pull-out behavior of corrugated steel fibers, Adv. Cement. Mater., 4(1), 1996, 28-41

[8] Sujivorakul C., Waas A.M., Guerrero P., Pull-out of a smooth fiber with an end anchorage. ASCE J. Mater. Civ. Eng., 126(9), 2000, 986-993

[9] Ezeldin A.S., Balaguru B.N., Bond behavior of normal and high-strength fiber reinforced concrete, $\mathrm{ACl}$ Mater. J., 86(5), 1989, 515-524

[10] Shannag M.J., Brincker R., Hansen W., Interfacial (fibermatrix) properties of high-strength mortar (150 MPa) from fiber pullout, ACI Mater. J., 93(5), 1996, 1-7

[11] Shannag M.J., Brincker R., Hansen W., Pullout behavior of steel fibers from cement-based composites, Cem. Concr. Res., 27(6), 1997, 925-936

[12] Orange G., Acker P., Vernet C., A new generation of UHP concrete: ductal damage resistance and microme- chanical analysis. In: Third international workshop on high performance fiber reinforced cement composites (HPFRCC3), Mainz, Germany, 1999, 101-111

[13] Morton J., Groves G.W., The cracking of composites consisting of discontinuous reinforced concrete, J. Mater. Sci., 9(9), 1974, 1436-1445

[14] Bartos P., Review paper: bond in fibre reinforced cements and concretes, Int. J. Cem. Comp Liw. Concr., 3(3), 1981, 159-77

[15] Li V.C., Wang Y., Baker S., Effect of inclining angle, bundling and surface treatment on synthetic fiber pullout from a cement matrix Comp, 21(2), 1990, 132-140

[16] Wang Y., Li V.C., Backer S., Analysis of synthetic fiber pullout from a cement matrix. In: Mindess S, Shah $\mathrm{SP}$, editors, Bonding in cementitious composites, MRS symposium proceedings, Pittsburgh (PA): Materials Research Society, 1988, 159-165

[17] Stang H., Li V.C., Krenchel H., Design and structural applications of stress-crack width relations in fiber reinforced concrete, Mater. Struct., 28(4), 1995, 210-219

[18] Lin Z., Kanda T., Li V.C., On interface property characterization and performance of fiber-reinforced cementitious composites, Concr. Sci. Eng., 1, 1999, 173-184

[19] Nammur G.G., Naaman A.E., A bond stress model for fiber reinforced concrete based on bond stress slip relationship, ACl Mater. J., 86(1), 1989, 45-57

[20] Naaman A.E., Namur G.G., Alwan J.M., Najm H.S., Fiber pullout and bond slip I: analytical study, ASCE J. Struct Eng., 117(9), 1991, 2769-2790

[21] Naaman A.E., Namur G.G., Alwan J.M., Najm H.S., Fiber pullout and bond slip II: experimental validation. ASCE J. Struct. Eng., 117(9), 1991, 2791-2800

[22] Dubey A., Fiber reinforced concrete: characterization of flexural toughness \& some studies on fibermatrix bond-slip interaction. PhD Thesis, University of British Columbia, 1999

[23] STUVO-rapport 102. Constructieve toepassingen van staalvezelbeton, Eindrapport van STUVO-cel 149, 1996, 77

[24] Soroushian P., Mirza F., Alhozaimy A., Bonding of Confined Steel Fiber Reinforced Concrete to Deformed Bars, ACl Materials Journal 91(2), 1994, 141-149

[25] Noghabai K., Behavior of Tie Elements of Plain and $\mathrm{Fi}$-brous Concrete and Varying Cross Section, $\mathrm{ACl}$ Structural Journal 97(2), 2000, 277-284

[26] Bigaj-van Vliet A.J., Bond of deformed reinforcing steel bars embedded in steel fiber reinforced concrete - State-of-the-art report, Delft Cluster, 2001, 65

[27] Grünewald S., Performance-based design of selfcompacting fibre reinforced concrete. PhD Thesis, Delft University of technology, 2004 
[28] Holschemacher K., Klug Y., Pull-out behaviour of steel fibres in self-compacting concrete. First International Symposium on Design, Performance and Use of SelfConsolidating Concrete, China, 2005, 523-532

[29] Cunha V., Pull-out behaviour of hooked-end steel fibres in self-compacting concrete, Report 07-DEC/E06, University of Minho, 2007

[30] Schumacher P., Rotation Capacity of Self-Compacting Steel Fiber Reinforced Concrete, PhD Thesis, Delft Univer-sity of technology, 2008

[31] Aslani F., Nejadi S., Evaluation and Comparison of Experimental Results to Determine the Bond Characteristics of Steel Fiber Reinforced Self-Compacting Concrete. Structural Engineering World Congress (SEWC), Como, Italy, $4^{\text {th }}-6^{\text {th }}$ April, 2011

[32] Cox H.L., The elasticity and strength of paper and other fibrous materials, British J. Appl. Phys., 3(1), 1952, 72-79

[33] Greszczuk L.B., Theoretical Studies of the Mechanics of the Fibre-Matrix Interface in Composites, Interfaces in Composites, ASTM STP 452, American Society for Testing and Materials, PhiladelphiA, 1969, 42-58

[34] Lawrence P., Some Theoretical Considerations of Fibre Pullout from an Elastic Matrix, J. Mater. Sci., 7(1), 1972, 1-6

[35] Gopalaratnam V.S., Shah S.P., Tensile Fracture of Steel Fibre Reinforced Concrete, ASCE J Eng Mec Div, 113(5), 1987, 635-652

[36] Nammur G.Ir., Naaman A.E., Clark S.K., Analytical Prediction of the Pull-out Behavior of Steel Fibres in Cementitious Matrices. Cement Based Composites: Bonding in Cemenitious Composites, In: Symposia Proceedings, V.114, Materials Research Societ, Pittsburg, 1988, 217-224

[37] Gopalaratnam V.S., Cheng J., On the Modelling of Inelastic Interfaces in Fibrous Composites. Cement Based Composites: Bonding in Cementitious Composites, In: Symposia Proceedings, V.114, Materials Research Society, Pittsburgh, 1988, 225-231

[38] Stang H., Li Z., Shah S.P., The Pullout Problem-the Stress Versus Fracture Mechanical Approach, ASCE J. Eng. Mech., 116(10) 1990, 2136-2150

[39] Takaku A., Arridge R.G.C., The Effect of Interfacial Radial and Shear Stress on Fibre Pullout in Composite Materials, J. Phys., 6, 1973, 2038-2047

[40] Hsueh C.H., Elastic Load Trnasfer from Partially Embedded Axially Loaded Fibre to Matrix, J. Mater. Sci. Let., 7(5), 1988, 497-500

[41] Hsueh C.H., Interfacial Debonding and Fibre Pullout Stresses of Fibre-Reinforced Composites, Mater. Sci. Eng., A123, 1990, 1-11

[42] HSueh, C.H. Interfacial Debonding and Fiber Pullout Stresses of Fiber Reinforced Composites II: Non- constant Interfacial Bond Strength, Mater. Sci. Eng., A 125, 1990, 67-73.

[43] Alwan J.M., Naaman A.E., Guerrero P., Effect of mechanical clamping on the pullout response of hooked steel fibers embedded in cementitious matrices, Concrete Sci. Eng., 1(1), 1999, 15-25

[44] Chanvillard G., Modeling the pullout of wire-drawn steel fibers, Cement Concrete. Res., 29(7), 1999, 10271037

[45] Morton J., Groves G.W., The effect of metal wires on the fracture of a brittle matrix composites, J. Mater. Sci., 11(4), 1976, 617-622

[46] Kanda T., Li V.C., Interface property and apparent strength of a high strength hydrophilic fiber in cement matrix, ASCE J. Mater. Civ. Eng., 10(1), 1998, 5-13

[47] Aslani F., Nejadi S., A Comparison of the Bond Characteristics in Conventional and Self-Compacting Concrete, Part I: Experimental Results, The $9^{\text {th }}$ Symposium on High Performance Concrete, Rotorua, New Zealand, Vol. 2, 2011, 435-442

[48] Aslani F., Nejadi S., A Comparison of the Bond Characteristics in Conventional and Self-Compacting Concrete, Part II: Code Provisions and Empirical Equations. The $9^{\text {th }}$ Symposium on High Performance Concrete, Rotorua, New Zealand, Vol. 2, 2011, 443-450

[49] Orangun C.O., Jirsa J.O., Breen J.E., A revaluation of test data on development length and splices, $\mathrm{ACl}$ Journal Proceeding 74(3), 1977, 114-122

[50] Kemp E.L., Wilhelm W.J., Investigation of the parameters influencing bond cracking, $\mathrm{ACl}$ Journal Proceeding 76(1), 1979, 47-71

[51] Kemp E.L., Bond in reinforced concrete: behavior and design criteria, ACI Journal Proceeding 83(1), 1983, 50-57

[52] Chapman R.A., Shah S.P., Early-age bond strength in reinforced concrete, $\mathrm{ACl}$ Materials Journal 84(6), 1987, 501-510.

[53] Harajli M.H., Development/splice strength of reinforcing bars embedded in plain and fiber reinforced concrete, ACl Structural Journal 91(5), 1994, 511-520

[54] Pillai S.U., Kirk D.W., Erki M.A. Reinforced concrete design, McGraw-Hill Ryserson, Whitby, ON, Canada, 1999

[55] Bae S., Mix design, formwork pressure and bond charac-teristics of special self-consolidating concrete, MSc Thesis, Ryerson University, 2006

[56] CEB. 1982, Bulletin D'Information No 151-Bond action and bond behaviour of reinforcement (State-ofthe- art report), CEB, Paris, France: p. 153

[57] Barbosa M.T.G., Evaluation of the behavior of the bond in ordinary and high strength concrete. Doctoral Thesis, COPPE/UFRJ, 2001 (in Portuguese)

[58] Aslani F., Nejadi, S., Bond Behavior of Reinforce- 
ment in Conventional and Self-Compacting Concrete. Advances in Structural Engineering. In Press.

[59] CEB-FIP, Structural Concrete-Bulletin No. 1. Paris, France, 1999

[60] Huang Z., Engström B., Magnusson J., Experimental in-vestigation of the bond and anchorage behaviour of de-formed bars in high strength concrete. Report 94:4, Chalmers University of Technology, 1996

[61] Harajli M.H., Hout M., Jalkh W., Local bond stressslip behaviour of reinforcing bars em1bedded in plain and fibre concrete, ACl Mater Journal 92(4), 1995, 343-353

[62] Harajli M.H., Local bond-slip behavior of reinforcing bars embedded in fiber reinforced concrete, In: Proceedings of international conference: Bond in concrete - From research to practice, Riga, 1992, 7.87-7.97

[63] Hartwich K., Zum Riss- und Verformungsverhalten von stahlfaserverstärkten Stahlbetonstäben unter Längszug, Dissertation, TU Braunschweig, Institut für Baustoffe, Massivbau und Brandschutz, Heft 72, Germany, 1986

[64] Samen Ezeldin A., Balaguru P.N., Bond performance of reinforcing bars embedded in fiber reinforced concrete and subjected to monotonic and cyclic loads, In: Proceedings of ASCE on Serviceability and Durability of Construction Materials, 1990, 145-154

[65] Hota S., Naaman A.E., Bond stress-slip response of reinforcing bars embedded in FRC matrices under mono-tonic and cyclic loading, $\mathrm{ACl}$ Structural Journal 94(5), 1997, 525-537

[66] Plizzari G.A., Bond and splitting crack development in normal and high strength fiber reinforced concrete, In: Proceedings of $13^{\text {th }}$ Eng. Mechanics Division Conference - EMD 9, Baltimore, 1999

[67] De Bonte F., Hechtsterkte bij staalvezelbeton, MSc Theis, Katholieke Universiteit Leuven, Belgium, 2000, 140

[68] Dupont D., Vandewalle L., De Bonte F., Influence of steel fibres on local bond behaviour, in: Bond in concrete - from research to standards, Balázs, G. et al. (ed.), 2002, 783-790

[69] Plizzari G.A., Lundgren K., Balázs G.L., Bond and Splitting in Fibre Reinforced Concrete under Repeated Loading, in: Bond in Concrete - from research to standards, Balázs, G. et al. (ed.), 2002, 221-229

[70] Weiße D., Verbundverhalten der Bewehrung in Stahlfaserbeton. 2. Leipziger Fachtagung "Innovationen im Bauwesen", Faserbeton, Bauwerk Verlag GmbH, Berlin, Germany, 2002, 77-88

[71] Pfyl Th., Tragverhalten von Stahlfaserbeton, Dissertation ETH Nr. 15005, Zürich, Switzerland, 2003

[72] $\mathrm{ACl}$ 318. 2008. Building code requirements for structural con-crete and commentary, American Concrete Institute 